\title{
The British Journal of
}

Occupational Therapy

\section{Individual Placement and Support (IPS) versus IPS enhanced with work-focussed CBT: feasibility study for a randomised controlled trial}

\begin{tabular}{|c|c|}
\hline Journal: & British Journal of Occupational Therapy \\
\hline Manuscript ID & 089-May-2015-RP.R1 \\
\hline Manuscript Type: & Research Paper \\
\hline Key Areas: & Adult Psychosocial < Clinical, Research Methods and Methodology \\
\hline Keywords: & IPS, Employment, Pragmatic Trial \\
\hline Abstract: & $\begin{array}{l}\text { Introduction } \\
\text { Employment is a key goal for many people with long-term mental health } \\
\text { issues. Evidence-based Individual Placement and Support (IPS) is a } \\
\text { widely-advocated approach. This study explored explore whether IPS } \\
\text { outcomes could be enhanced with work-related counselling. } \\
\text { Method } \\
\text { The study was designed as a pragmatic RCT comparing the cost- } \\
\text { effectiveness, in severe mental illness, of work-focussed intervention } \\
\text { (intervention) as an adjunct to IPS compared to IPS alone (control). } \\
\text { Results } \\
\text { The original sample ( } 330 \text { ) proved impossible to attain so the design was } \\
\text { revised to a pilot study from which information on feasibility of a full trial } \\
\text { could be drawn. } 25 \text { individuals out of } 74 \text { found paid work but no difference } \\
\text { was found in the mean number of hours in paid employment between the } \\
\text { intervention and control groups. } \\
\text { Conclusion } \\
\text { Results demonstrate that delivering work-focussed counselling in tandem } \\
\text { with IPS is feasible and acceptable to service users. The study observed } \\
\text { that, even during a period of recession ( } 2010-13 \text { ), individuals with mental } \\
\text { health problems succeeded in obtaining paid employment. } \\
\text { Implications } \\
\text { Any additional benefit of counselling over IPS alone could not be } \\
\text { ascertained, due mainly to the high drop-out rate from this } \\
\text { study. Implications for occupational therapy and for future trials of IPS are } \\
\text { discussed. }\end{array}$ \\
\hline
\end{tabular}




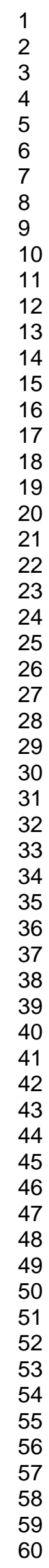

2

4

5

6
7

8

10

11

12

.

14

16

17

19

20

.

23

24

26

27

29

30

32

33

35

36

37

38

39

40

41

42

44

45

46

47

48

49

50

52

53

54

56

57

58

60 


\section{Introduction}

Occupational therapists have always been at the vanguard of innovation and development in promoting employment for people with mental health problems, both in the UK (Rinaldi \& Perkins, 2007) and beyond (Waghorn et al., 2009). The approach called Individual Placement and Support (IPS) has a good evidence base (Burns et al., 2007; Marwaha et al., 2007; Kinoshita et al., 2013, Marshall et al., 2014, Drake \& Bond, 2014) but its implementation is exacting in many ways. For instance, it requires co-location of employment support staff with community mental health staff, and this can present organisational barriers. Also, IPS employment support workers should have caseloads of about 20 , enviably low compared to caseloads of most community mental health team members (Swanson and Becker, 2011, Schneider and Akhtar, 2012). In short, while IPS is increasingly widely-adopted in the UK, it cannot be said to be part of 'standard' mental health services.

\section{Literature review}

There has been a call for a 'more formal evidence base for occupational therapy interventions in the field of supported employment' (Priest and Jones, 2010). Arbesman and Logsdon (2011) reviewed the OT literature on employment support and concluded that IPS had 'strong evidence' in its favour but its outcomes were stronger in combination with cognitive or social skills training. Our earlier review concluded that more evidence was needed concerning the potential to increase the power of IPS by combining it with adjunct interventions (Boycott et al., 2012). There is increasing evidence that on its own IPS results in significant cost offsets by increasing the proportion of clients who work (Bush et al., 2009; Kilian et al., 2011; Perkins et al., 2005; Schneider et al., 2009). In terms of both days worked and whether the individual had worked at least for one day, IPS generated improvements and was cost-saving from the point of view of the health and social care systems (Knapp et al., 2013). However a key question about enhancing IPS is the whether the additional cost of the enhancement is warranted by the benefits.

The present study aimed therefore to test the hypothesis that work-focussed counselling as an adjunct to IPS will prove more successful in helping people with schizophrenia and 
related disorders into paid employment than IPS alone. The design was a two-arm, parallel, randomised controlled trial of enhanced IPS versus IPS alone, with a costeffectiveness arm added because of previous findings cited above. By taking a pragmatic and exploratory approach we sought also to investigated whether participation might affect engagement with education, training and volunteering, as well as the implications of the findings for the wider implementation of IPS. Here, we report on the results of the main outcome, paid employment in the open labour market, and on the take-up of education, training and volunteering, together with the results of the costs analysis. The implications for the wider implementation and evaluation of IPS are also considered in our discussion below.

\section{Method}

Setting

This context for this study was a Collaborative for Leadership in Applied Health Research and Care (CLAHRC), focusing on putting evidence into practice (Rowley et al., 2012). The study was undertaken in one mental health provider, Nottinghamshire Healthcare NHS Trust. A preliminary phase put in place a fully-operational IPS service through the appointment of an IPS Development Manager for two years (Schneider and Akhtar, 2012). Following this period, the present study recruited participants from the caseloads of one Community Mental Health team ('Rehabilitation and Recovery') and one Early Intervention in Psychosis (EIP) team based within Nottinghamshire Healthcare NHS Trust (NHCT) in 20102012. A positive ethical opinion was granted by Derbyshire Research Ethics Committee (ISRCTN18240558).

\section{Inclusion and Exclusion Criteria}

People who consented to participate were eligible if they were aged 18-60 and on the caseload of the Rehabilitation and Recovery or EIP teams. We excluded anyone who was an inpatient at the time of the invitation to participate, people currently in work or in education and those not wishing to work, anyone who was unable to give informed consent, and anyone who was already receiving cognitive behaviour therapy (CBT). Provision was made to employ interpreters but none required this support. The initial approach to service 
users was made by their usual care co-ordinators and interested parties responded directly to the research team or via the care co-ordinator.

\section{Randomisation}

The researcher, after gaining informed consent, entered participants' details onto a webbased randomisation system. Group allocation was sent directly via encrypted email to an administrator, who forwarded details to the psychologist delivering the intervention.

Details of allocation were kept by the administrator and psychologist in password-protected files. The psychologist made contact with participants in the intervention arm to inform them of their allocation. The researcher responsible for assessing participants at baseline and follow-up was thus 'blind' to allocation until all data collection had been completed.

\section{Interventions}

Treatment as usual - IPS

On enrolment to the study participants were assigned to an Employment Specialist (an IPStrained worker) who met with them at a mutually-agreed location (often the participant's home) to produce an action plan for employment. Participants continued to meet with their Employment Specialist as often as they wished, in keeping with the responsive ethos of the intervention. The key objectives and methods of working within an IPS model are well established (Dartmouth IPS Supported Employment Center, 2012). Broadly, this entails intensive, individualised, employment-focussed advice and practical support without time limit. The fidelity of the particular IPS service provided for the study was measured in October, 2010, at the start of recruitment, by an independent team who visited the site, following the 25-point Fidelity Scale published online as IPS Resources for Trainers and Fidelity Reviewers (IPS Dartmouth Supported Employment Center, 2015). The preliminary score was 63, 'not IPS', because all the community mental health teams had been merged into one, creating a highly diluted IPS service, and reviewers commented that “...there will need to be structural changes to the way the service is managed if it is to deliver the outcomes expected of a high fidelity service". Since changing mental health services structures was beyond the scope of the study, after recruiting 17 participants, in order to achieve a more rigorous model of IPS, the focus of recruitment shifted to a team dealing 
with early psychosis, where the remaining 57 participants joined the study by June, 2012 . This team was smaller, working with a younger clientele and more amenable to implementing IPS fully. The next external fidelity review, in February 2012, scored the service fidelity as 'good' with 101 points.

\section{Work-Focussed Counselling Intervention}

In addition to IPS as described above, participants randomised to the intervention arm of the trial were offered 3-6 sessions of work-focussed counselling delivered by a psychologist. This intervention was developed and piloted as part of the present study; informed by previous studies (Coldham et al., 2002; Rose and Perz, 2005; Boycott et al., 2012) and based on generic psychological practice, including goal-based motivational procedures and cognitive behaviour therapy (CBT). This work-focussed counselling intervention was designed to enhance the impact of IPS by addressing common obstacles to employment which are not directly due to symptomatology (e.g. hallucinations) and not normally the concern of the clinical team (e.g. medication adherence). An intervention manual based on a life goals and a problem solving approach was developed and supplemented by self-help materials. It was delivered by a trained psychologist (NB) with individual participants. Each received a booklet ('Working Well!') containing information about six topics (anxiety, depression, self-esteem, memory/concentration, stigma and getting on with others) and was asked to choose a maximum of four topics to discuss with the psychologist over up to 6 sessions lasting about an hour, mostly taking place in the participant's home. The intervention was independently evaluated using a qualitative approach and this is reported in Boycott, Akhtar and Schneider (2015).

\section{Outcomes}

\section{Primary}

The main outcome was the total number of hours in paid employment (in the open labour market) 6 months after entering the trial. Whereas many IPS studies use a bivariate measure of whether or not a person was in work at the primary end point, the fact that both intervention and control groups were both in receipt of IPS led us to adopt a measure that would reflect differences in overcoming barriers to sustained employment, such as 
work-focussed counselling was designed to impart. Hence the amount of time in the workplace was chosen to differentiate the intervention and control groups at six months. Secondary

The study was implemented at a time of economic recession in the UK, which seemed likely to adversely affect the job prospects of participants, so vocational activities such as education, training and volunteering were also measured. The questionnaires used are listed in Table 1. They include the Rosenberg Self-Esteem Scale (Rosenberg, 1965), the EQ5D (EuroQOL Group, 1990) and the Client Service Receipt Inventory (Beecham and Knapp, 1992) which yield data required for estimating and comparing costs, and the SF-12 which measures health and wellbeing (Ware et al., 2002). Less widely-used measures were applied to explore the impact on self-assessed barriers to work (Lerner et al., 2004a, 2004b) perceived stigma (Schneider et al., 2011), avoidance of social disapproval (Leary, 1983), social cognition (Burgess et al., 1996) and social problem solving (D'Zurilla et al., 2002).

Table 1 about here

The researcher assessed participants face-to-face at baseline, 6 and 12 months and by telephone at 9 months. Demographic, work and education history and clinical details were gathered at baseline. At baseline, 3, 6, 9 and 12 months, the researcher collected data about working hours, welfare benefits received and services used (excepting the experimental intervention). Secondary outcome measures shown in Table 1 were administered at baseline, 6 and 12 months to both groups. At about 9 months, qualitative interviews were held with an opportunistic sample of 31 individuals, to explore the participants' experience of the intervention, their satisfaction with the process and how it could be improved.

\section{Sample size and amendments}

The original sample size calculations derived from estimates that $25 \%$ of the control group and $40 \%$ of the intervention group would obtain work. While this estimate was informed by the IPS literature (e.g. Bond et al., 2008), the pragmatic nature of the study led us to adopt conservative employment rates for both arms of the trial. For an $80 \%$ power of 
demonstrating this difference $(p<0.05), 165$ participants were required in each arm of the trial. Recruitment during the first 6 months was 17 and it emerged that one Employment Specialist's caseload capacity was constrained by pre-existing clients, while as noted above organisational restructuring made IPS fidelity inadequate. Application was therefore made to the ethics committee for a substantial amendment to enable the study to recruit from an Early Intervention in Psychosis team, while the target sample size was revised downwards to a minimum of 28 per arm on the basis of what would be feasible within the constraints of the funding and remaining time available. The amendment also extended three psychometric measures (DEX, SPSI-R and BFNE, 20-22), which had initially only been used with the intervention group, to be used with all participants. This was to assess any treatment affects, which we expected to be greater in the intervention group. The possible sample size for the DEX, FNE and SPSI was therefore reduced by 17 because these measures were only introduced after that number of participants had been recruited.

\section{Statistical analysis}

The primary analysis was intention-to-treat and included all participants who were randomly assigned to their respective groups (intervention or control), regardless of whether they engaged with IPS/enhanced IPS or not. Participants who were lost to followup were assumed to be not working and the number of hours was recoded as zero.

\section{Costs estimation and analysis}

To estimate costs, we multiplied frequencies obtained by, in most but not all cases, PSSRU unit costs for 2012 (PSSRU, 2013). Details are in the Appendix. For the purpose of examining the distributions of the values, we prorated available data to obtain annualized, and thus comparable, numbers. Having done this, we calculated means by group. We also used box plots to compare the distributions of paid hours post-baseline for the intervention and control groups, as well as improvement in paid hours (adjusting for baseline differences).

Bootstrapping and multiple imputation were used to both estimate the incremental costeffectiveness ratio (ICER), and assess uncertainty in the ICER. We began by obtaining 1000 
sample replicates using bootstrapping. For each sample, we used multiple imputation (with 20 imputed data sets) to calculate a mean cost and mean effect. These were plotted on a cost-effectiveness plane. From the location of the points on the cost-effectiveness plane, a cost-effectiveness acceptability curve was derived. This procedure also is used to compute an ICER and a standard error for the ICER; 'bootstrap' and 'mi' procedures in Stata 13 were used to calculate this.

Finally, we examined bivariately whether there appeared to be an association between paid hours, or improvement in paid hours, on the one hand, and on the other hand, the number of hours of psychological intervention received. If the psychological intervention increased paid hours, one would expect to see a dose-response relationship.

\section{Results}

Seventy four individuals were recruited to the study from August 2010 to June 2012, 37 randomised to each arm. In total, 32 of these individuals (43\%) were lost to follow-up (see Consort diagram). Their destinations up are unknown but in the analysis we assume they were not working.

\section{Adverse events}

One participant committed suicide during the trial, but this was judged to be due to a significant mental health relapse and not related to participation in the study. No other adverse effects were reported.

\section{Attrition}

Attrition analyses were conducted in relation to gender, age, clinical history and the secondary outcome measures. Independent t-tests showed a statistically significant difference for age; individuals who stayed in the study were older with a mean age of 32.23 (s.d. 9.69) as compared to 27.03 (s.d. 9.32) ( $t=-2.33$, $d f=72, p<.05)$. No other differences were found for individuals who stayed in the study in comparison to those who were lost to follow-up at each time-point.

Figure 1 (Consort Diagram) about here 


\section{Demographic and Clinical Characteristics}

Table 2 shows the demographic and clinical characteristics of the entire sample.

Independent t-tests and non-parametric Mann Whitney U-tests were conducted to compare the two groups' demographic and clinical characteristics. No significant differences were found, suggesting that the two groups were equally matched at baseline for age, ethnicity, marital status and clinical history.

\section{Table 2 about here}

\section{Primary Outcome}

In relation to the primary outcome, hours per week (hpw) of (paid) employment after six months, the mean hpw worked was 3.22 (s.d. 9.53) for the 37 individuals who were part of the control group, and $3.89 \mathrm{hpw}$ (s.d. 10.60) for the 37 individuals who were part of the intervention group. At 12 months the mean number of hours worked by individuals who were part of the control group ( $N=37$ ) was 3.67 (s.d. 7.80 ) and 7.07 (s.d. 14.09) for individuals who were part of the intervention group $(\mathrm{N}=37$ ) (Table 3). Using the MannWhitney $U$ test, no statistically significant difference was found between the intervention and control groups in relation to the main outcome; mean number of hours worked per week at 6 months $(z=0.57, p=0.56)$ and this was also true at 12 months $(z=0.71, p=0.48)$. Twenty five out of 74 people entered employment over the course of the study. Of this number, 12 were working full time, defined as 35-45 hours hpw, 3 worked 20-30 hpw, 6 worked 10-16 hpw and 4 less than $10 \mathrm{hpw}$.

There were no statistically significant differences between the two groups at any time point on the secondary outcome measures.

In terms of voluntary work and education/training, 12 participants started voluntary work and 9 entered education/training during the study. This group comprised 7 individuals from the control group and 5 individuals from the intervention group who were volunteering and 3 individuals from the control group and 6 individuals from the intervention group who were in education/training. There were no statistically significant differences for voluntary work between the two groups $\left(\mathrm{Chi}^{2}=0.39, \mathrm{df}=1, \mathrm{p}=0.53\right)$ nor for education/training between the control or intervention group $\left(\mathrm{Chi}^{2}=1.14, \mathrm{df}=1, \mathrm{p}=0.28\right)$. 


\section{Reasons for attrition}

The reasons for attrition are shown in the Consort Diagram (Fig 1). These are similar for both arms of the trial: equal numbers people declined IPS with treatment as usual (control), and the work-focussed counselling with IPS (intervention). Thereafter, the loss to study rates are not remarkably different: three people left the country following baseline assessment, all happened to be in the TAU arm of the trial, while one person from the intervention arm sadly died through suicide. Otherwise people were too unwell or declined the follow-up interviews, despite careful steps taken to engage their co-operation; letters were sent to participants who declined, informing them about the importance of staying in the study and their care coordinators were repeatedly contacted to try and re-engage them back into study. Generally, those who left the study were affected by severe mental illness or felt that they had gained little from participation. The people who obtained work remained in contact with the study, with one exception.

\section{Figure 1 about here}

\section{Secondary Outcomes}

Table 4 shows that mean scores for self-esteem, stigma, physical and mental health and for problem-solving measures did not differ significantly between the two study groups. No difference was found at an individual level for most of the secondary outcomes between baseline and 6 months and baseline and 12 months, with three exceptions. Due to the number of t-tests applied, and given the contradictory interpretations of these findings, they may well be due to chance but they are reported here for future reference:

At an individual level, for the entire study sample, repeated measures t-tests indicated significant change in the mean health state score on the EQ-5D between baseline (65.78) and 6 months $(70.63)(t=-1.98, d f=51, p<.05)$ and this was also true comparing baseline (64.95) to 12 months $(71.11)(t=-2.28, d f=41, p<.05)$. The results suggest that individuals perceived their health status to worsen over time.

By contrast, significant difference was found in the vitality scale of the SF-12v2 measure. 'Vitality' measures how much of the time the respondent felt energetic. Vitality scores increased between baseline (2.83) and 12 months (3.19) $(\mathrm{t}=-2.35, \mathrm{df}=41, \mathrm{p}<.05)$. 
Thirdly, change was found in the brief fear of negative evaluation scale scores between baseline (37.10) and 6 months (34.12) $(t=2.37, d f=38, p<.05)$, suggesting that individuals' fear of negative evaluations significantly decreased between baseline and 6 months.

\section{Additional Analysis}

As an aside from the ITT analysis, if we look post-hoc at the people who took up the opportunity to engage with the psychotherapeutic input, there is an indication that this made a difference. Of the 29 people who took up the experimental intervention, 12 obtained employment (41\%), compared to 13 of the 45 (29\%) who did not receive the experimental intervention ( 37 who were randomised to IPS-only group plus 8 who were randomised to the IPS+ group but did not attend intervention). Although there were no statistically significant differences between groups $\left(\mathrm{Chi}^{2}=0.73, \mathrm{p}=0.39\right)$, for the people who received the experimental intervention, the odds ratio of obtaining employment was 1.74 $(95 \% \mathrm{Cl}=0.65-4.63)$, suggesting a positive effect of receiving intervention.

Furthermore, in terms of retention within the trial and in IPS services, fewer of those who received the work-focussed counselling intervention dropped out than those who had not received the intervention. Nine of the 29 participants who received intervention dropped out of the RCT (31\%), compared with 23 of the 45 participants who received IPS alone (51\%). Again, this difference was not statistically significant $\left(\mathrm{Chi}^{2}=2.14, \mathrm{df}=1, \mathrm{p}=0.14\right)$, but the odds ratio of $0.43(95 \% \mathrm{Cl}=0.16$ - 1.14$)$ suggests a positive effect of receiving the intervention.

\section{Costs}

Table 4 provides means and standard deviations of paid hours, use of services, cost subtotals and total costs, by group, at baseline and during the subsequent 12-month time period. The data contained a number of missing values. Some individuals had no data beyond the baseline assessment. These were dropped from the cost-effectiveness analysis. Others had at least data for the 3-month period. All cost values, both pre- and postbaseline, are expressed as over a 3-month period. 
Paid hours appear somewhat higher for the intervention group, both at baseline and during the 12-month, post-intervention period. Also, total costs are somewhat lower for the intervention group pre-baseline, and somewhat higher post-baseline, a difference that arises only partly from the cost of the intervention itself, which averages to $f 136$. More detailed observation of the distribution of resource use and costs indicated that this difference was partly due to one participant assigned to the intervention group, who had an unusually long hospitalization (70 days) towards the end of the one-year post-baseline period. The participant with the next-highest number of days, who was assigned to the control group, had 12 days. No other participant was hospitalized. We removed the outlier from the sample and redid the above calculations as a sensitivity analysis, the results are shown in Table 4. In order to assess the influence of the multiple imputation procedure on the results, we also did the calculations, including the individual with a high number of hospital days, by prorating costs and paid hours rather than by using multiple imputation. It is important to note that in either case the data in Table 4 show no indication of a possible cost offset.

Figures $2 a \& b$ about there

Figures $3 a \& b$ about here

Figure 2 a represents the base case - multiple imputation with complete data. The data suggest that the intervention is associated with a greater number of paid hours (though the standard error is greater than the mean - the difference is not statistically significant); it is also more costly. Costs of the work-focussed intervention were estimated at $£ 136$ per person on average. Only if the decision-maker is willing to pay about $f 100$ per paid hour does the intervention reach a $50 \%$ chance of being cost-effective. If we remove the individual who had 70 hospital days from the analysis, Figure $2 \mathrm{~b}$ shows that the difference in cost between the groups diminishes, without affecting the difference in effectiveness, so that the apparent cost-effectiveness rises. (Recall that this individual had been assigned to the intervention group.) The decision-maker needs to be willing to pay about $£ 30$, rather than $f 100$, per paid hour for the intervention to reach a $50 \%$ chance of being cost-effective. Still, even if the decision-maker were willing to pay $£ 100$ per paid hour, the probability of the intervention being cost-effective would only reach about $66 \%$. 
Finally, Figures $3 a$ and $3 b$ suggest that, if one abstracts from two unusual individuals with, in one case, no hours of intervention but a high number of paid hours per week, and in the other case, 9 hours of psychological intervention but no paid hours, there does seem to be a possible dose-response relationship between hours of work-focused psychological intervention and paid hours.

\section{Discussion and implications}

We found no statistically significant differences between IPS alone and IPS with workfocussed counselling at any time point on the primary or secondary outcome measures. While the study does provide some modest encouragement for exploring further the potential for enhancing IPS with some form of work-focussed counselling, the adjunct intervention would need to produce a practically significant increase in hours worked to be considered cost-effective. Waghorn et al. (2009, Table 2) list a range of opportunities for occupational therapists to enhance employment support for people with mental health problems, through their professional input as advocates, consultants and practitioners. The findings reported here may be read in the light of other evidence about 'work-related selfefficacy', which the same authors define as 'confidence to perform core activities at a specific task level', and put forward as an area where occupational therapy expertise is relevant.

The results also raise a number of learning points which should inform the implementation of such interventions and the design of future trials of this or similar occupational therapy interventions. First, the planned sample size was overoptimistic. Despite full co-operation from senior managers in the service studied and a context amenable to research, organisational issues - reorganisation, overcrowded offices, and the availability of care coordinators to provide the practical help required to implement the trial, proved disadvantageous. Second, provision of employment specialists proved more irregular than intended. Altogether there were 30 months of employment support worker time invested in the study over a time period of 2 years to treat 74 people. In fact, some people $(N=10)$ received only two months of employment specialist support. Studies of IPS (e.g. Perkins, 2005; Rinaldi and Perkins, 2007; Boyce et al., 2008) highlight the importance to service 
users' confidence of the continuity of this contact. Thirdly, the work-focussed counselling intervention was very much a pilot. Six sessions were offered, but participants could stop at any point. Only six people took up all available sessions and it is unlikely that a low-intensity intervention would be very powerful. It is also possible that study's intervention was not sufficiently different from standard IPS in the benefits derived by individual service users. Both constituted a supportive relationship with a focus on real-world problems; perhaps that is sufficient to enable a person to pursue his or her work aspirations effectively.

Two further issues were raised in the implementation of the study. Difficulties were experienced in completing some of the psychosocial measures, in particular the DEX and BFNE. More straightforward and user-friendly measures would be preferable if the trial were to be repeated. Furthermore, the addition of specific anxiety and depression measures would be helpful considering the popularity of the anxiety and depression topics among participants. Although receiving CBT was an exclusion criterion for the study, it emerged that a number of participants $(N=8 ; 5$ intervention and 3 control) did in fact start seeing clinical psychologists receiving CBT-type therapy after entering the study, either weekly (3) or fortnightly (5). Given the strong CBT evidence base, future trials should postpone the start of generic CBT while employment-focussed interventions are being studied.

\section{Limitations}

The high drop-out rate is the major limitation to this study. Of the 32 who dropped out, 15 were part of the intervention arm and 17 were lost to the control arm. Although no differences were found in the clinical profile nor the psychometric scores of these two arms, younger individuals and those who were not actively using the services on offer were more likely to drop out of the study. Younger individuals present greater likelihood of relapse and therefore this could have increased the probability of their dropping out (Lysaker and France, 1999).

A hostile labour market prevailed throughout the period of the trial with escalating unemployment figures in the general population. The effects on the trial cannot be 
ascertained, but comparison can be made between the study participants and people across England and Wales who were unemployed and receiving Job Seeker Allowance during the same period: The Department of Work and Pensions (DWP) apply an outcome criterion of 13 weeks of continuous paid work, and the national results of the DWP Work Programme were reported in September 2013 (Centre for Economic and Social Inclusion, 2013). This found that $11 \%$ of the general unemployed population, who were not known to have severe mental illness, succeeded in attaining employment between July 2012 and June 2013. If we apply the same 13 -week continuous employment measure, $20 \%$ of the participants in this study succeeded retaining work for 13 weeks within 12 months despite the disadvantage of severe mental health problems.

\section{Conclusion}

The learning points about the study could inform future studies. While the hypothesis that work-focussed counselling would make a significant improvement to IPS outcomes was not supported by the trial, the data demonstrate that, even during a recession, people with severe mental health problems can be helped to attain employment through the IPS approach. Comparison with the general population suggests that the effects of the recession were not as detrimental to the participants in our study as to the unemployed population as a whole. This may arguably be because the IPS approach is more effective than other employment support approaches available to the general population.

\section{Key message}

Occupational therapy can offer promising enhancements to IPS, but evaluating their marginal benefit would require a robust design that is protected against the vicissitudes of organisational change in the care environment.

\section{What the study has added}

The study has shown that IPS can be successfully delivered despite a negative economic climate in a UK context, and that it is feasible deliver work-focussed counselling as an adjunct intervention.

\section{Competing interests}


The authors declare that they have no competing interests.

\section{Authors' contributions}

AA obtained ethical clearance, collected the data and undertook data analysis, NC designed, delivered and evaluated the psychological intervention, overseen by MM who also undertook the additional analysis. BG analysed the data and generated the statistical comparisons. EL oversaw the costs analysis, while ZC performed this. JS conceived, managed and led the study. All authors contributed to the manuscript and approved the final version.

\section{Acknowledgements}

Phil Bilzon, Erica Bore, Emma Holmes, Professor Peter Liddle, Maria Griffin, Catherine Pope, Jayne Simpson, Julie Swann, Nigel Taylor, Eric Wodke and Shirley Woolley contributed their skills and knowledge to this study. We are grateful to the community health teams that participated and of course above all to the individuals who consented to join this study. The research was funded by the NIHR CLAHRC-NDL programme (2008-2013). The views and opinions expressed here are those of the authors and do not necessarily reflect those of the CLAHRC-NDL programme, NIHR, NHS or the Department of Health. Grant number RC08B2. 


\section{References}

Arbesman M and Logsdon DW (2011) Occupational therapy interventions for employment and education for adults with serious mental illness: a systematic review. American Journal of Occupational Therapy 65 (6), 238-46.

Becker DR, Smith J, Tanzman B, et al. (2001) Fidelity of supported employment programs and employment outcomes. Psychiatric Services, 52, 834-836.

Beecham J and Knapp M (1992) Costing psychiatric interventions. In Thornicroft G, Brewin C and Wing J (eds.) Measuring Mental Health Needs. London: Gaskill, pp179-190.

Bond GR, Becker DR, Drake RE et al. (1997) A fidelity scale for the Individual Placement and Support model of supported employment. Rehabilitation Counselling Bulletin, 40, 265-284. Bond GR, Drake RE, and Becker DR (2008) An update on randomized controlled trials of evidence based supported employment. Psychiatric Rehabilitation Journal, 31, 280-289. Boyce, M, Secker, J, Johnson, R, et al. (2008) Mental health service users' experiences of returning to paid employment. Disability and Society, 23(1) 77-88.

Boycott N, Akhtar A, Schneider J (2015) "Work is good for me": views of mental health service users seeking work during the UK recession, a qualitative analysis. Journal of Mental Health, 24 (2) 93-97.

Boycott N, Schneider J, McMurran M (2012) Interventions to Enhance the Effectiveness of Individual Placement and Support: A Rapid Evidence Assessment, Rehabilitation Research and Practice Article ID 382420, 8 pages, doi:10.1155/2012/382420.

Burgess PW, Alderman N, Wilson BA et al. (1996) Validity of the battery: Relationship between performance on the BADS and ratings of executive problems. In BA Wilson (Ed.), BADS: Behavioural assessment of the dysexecutive syndrome manual. Bury St Edmunds, UK: Thames Valley Test Company pp. 18-19.

Burns T, Catty J, Becker T, et al. (2007). The effectiveness of supported employment for people with severe mental illness: a randomised controlled trial. The Lancet 370: 1146-1152. doi: 10.1016/S0140-6736(07)61516-5

Bush P, et al. (2009) The long-term impact of employment on mental health service use and costs for persons with severe mental illness. Psychiatric Services 60(8): 1024-31. 
Centre for Economic and Social Inclusion (2013) Briefing paper: Measuring Work

Programme performance. Retrieved from:

http://stats.cesi.org.uk/Measuring WP Performance.pdf

Coldham EL, Addington J, Addington D. (2002) Medication adherence of individuals with a

first episode of psychosis. Acta Psychiatrica Scandinavica 106 (4): 286-290.

D'Zurilla TJ, Nezu AM and Maydeu-Olivares A (2002) Manual for the Social Problem-Solving Inventory, Revised. London: Multi-Health Systems. (www.mhs.com)

Dartmouth IPS Supported Employment Center (2012) Core Principles of IPS Supported

Employment. Dartmouth IPS Supported Employment Center.

http://www.dartmouth.edu/ ips/page29/page31/page31.html.

Drake, RE, and Bond, G. (2014) Introduction to the special issue on individual placement and support. Psychiatric Rehabilitation Journal, 37(2), 76-78.

EuroQol Group (1990) EuroQol: a new facility for the measurement of health related quality of life. Health Policy 16: 199-208.

IPS Dartmouth Supported Employment Center IPS Resources for Trainers and Fidelity Reviewers http://www.dartmouthips.org accessed 2592015.

Kilian, R et al. (2011) The relationships between employment, clinical status, and psychiatric hospitalisation in patients with schizophrenia receiving either IPS or a conventional vocational rehabilitation programme. Social Psychiatry and Psychiatric Epidemiology 47(9): 1381-1389.

Kinoshita Y, Furukawa TA, Kinoshita K, Honyashiki M, Omori IM, MarshallM, Bond GR, Huxley P, Amano N, Kingdon D. (2013) Supported employment for adults with severe mental illness. Cochrane Database of Systematic Reviews, Issue 9. Art. No.:CD008297. DOI: 10.1002/14651858.CD008297.pub2.

Knapp M, Patel A, Curran C, et al. (2013) Supported employment: cost-effectiveness across six European sites. World Psychiatry 12(1): 60-68. doi:10.1002/wps.20017

Leary MR (1983). A Brief Version of the Fear of Negative Evaluation Scale. Personality and Social Psychology Bulletin 9 (3): 371-375. doi: 10.1177/0146167283093007 
Lerner D, Adler DA, Chang H et al. (2004a) The clinical and occupational correlates of work productivity loss among employed patients with depression. Journal of Occupational and Environmental Medicine 46: S46-S55.

Lerner, D, Adler, DA, Chang, $\mathrm{H}$ et al. (2004b) Unemployment, job retention and productivity loss among employees with depression. Psychiatric Services 55: 1372-1378.

Lysaker PH, and France CM (1999) Intervention as an element in supported employment for persons with severe and persistent mental illness. Psychiatry 62(3): 209-221.

Marshall T, Goldberg, RH, Braude L, Dougherty RH, Daniels AS, Ghose SS, Preethy G, DelfinRittmon ME (2014) 2014, Supported Employment: Assessing the evidence. Psychiatric Services 65(1): 16-23.

Marwaha S, Johnson S, Bebbington P et al. (2007) Rates and correlates of employment in people with schizophrenia in the UK, France and Germany. British Journal of Psychiatry 191: 30-37. doi: 10.1192/bjp.bp.105.020982

Perkins DV, et al. (2005) Program evaluation from an ecological perspective: supported employment services for persons with serious psychiatric disabilities. Psychiatric Rehabilitation Journal 28(3): 217-24.

Priest B and Bones K (2012) Occupational therapy and supported employment: is there any added value? Mental Health and Social Inclusion 16: 194-200.

PSSRU (2013) Unit Costs of Health and Social Care. Available at: http://www.pssru.ac.uk/project-pages/unit-costs/2012/

Rinaldi M and Perkins R (2007) Implementing evidence-based supported employment. Psychiatric Bulletin 31: 244-249.

Rose V. and Perz J (2005) Is CBT useful in vocational rehabilitation for people with a psychiatric disability? Psychiatric Rehabilitation Journal 29:56-58.

Rosenberg M (1965) Society and the adolescent self-image. New York: Basic Books. Rowley, E, Morris, R, Currie, G et al. (2012) Research into practice: Collaboration for Leadership in Applied Health and Social Care Research (CLAHRC) for Nottinghamshire, 
Derbyshire, Lincolnshire (NDL). Implementation Science 2012; 7:40. doi: 10.1186/17485908-7-40.

Schneider J, Boyce M, Johnson R et al. (2009) Impact of supported employment on service costs and income of people with mental health problems. Journal of Mental Health 18(6): 533-542.

Schneider J, and Akhtar A (2012) Implementation of Individual Placement and Support: The Nottingham Experience. Psychiatric Rehabilitation Journal 35 (4): 325-332.

Schneider J, Beeley C, and Repper J (2011). Campaign appears to influence subjective experience of stigma. Journal of Mental Health 20(1) 89-97.

Schneider J, et al. (2009) Impact of supported employment on service costs and income of people with mental health needs. Journal of Mental Health 18(6): 533-542.

Swanson, S \& Becker, D (2011) Supported employment: A practical guide for practitioners and supervisor. 2nd edition. Hazelden Publishing \& Educational Services, Center City, Minnesota.

Waghorn, G, Lloyd, C, Clune, A. (2009) Reviewing the theory and practice of occupational therapy in mental health rehabilitation, British Journal of Occupational Therapy 72(7) 314323.

Ware JE, Kosinski M, Turner-Bowker DM et al. (2002) How to Score Version 2 of the SF-12 Health Survey (With a Supplement Documenting Version 1). Lincoln, RI: Qualitymetric Incorporated. 
Table 1 Secondary outcome measures

\begin{tabular}{|l|l|}
\hline \multicolumn{1}{|c|}{ Measure } & Items \\
\hline Rosenberg Self-Esteem Scale (Rosenberg, 1989)[22] & 10 \\
\hline Work Limitations Questionnaire (Lerner et al, 2004a ; 2004b) [23, 24] & 25 \\
\hline Stigma Survey (Schneider et al., 2011) [25] & 26 \\
\hline Dysexecutive Questionnaire (DEX; Burgess et al., 1996) [26] & 20 \\
\hline Social Problem Solving Inventory - Revised (D'Zurilla et al., 2002) [27] & 25 \\
\hline Brief Fear of Negative Evaluation (Leary, 1983) [28] & 12 \\
\hline Client Service Receipt Inventory (Beecham and Knapp, 1992) [29] & 27 \\
\hline Short Form Health Questionnaire (SF-12v2; Ware et al., 2002) [30] & 12 \\
\hline EQ5-D (The Euroqol Group, 1990) [31] & 5 \\
\hline
\end{tabular}


Table 2 Baseline demographic and clinical characteristics

\begin{tabular}{|c|c|c|}
\hline Demographics and History & $\begin{array}{l}\text { IPS Only (N=37) } \\
\text { (Control) }\end{array}$ & $\begin{array}{l}\text { IPS +Psychological } \\
\text { Intervention ( } \mathrm{N}=37) \\
\text { (Experimental) }\end{array}$ \\
\hline \multicolumn{3}{|l|}{ Gender } \\
\hline Male & 26 & 26 \\
\hline Female & 11 & 11 \\
\hline Mean Age & 29.48 & 30.48 \\
\hline \multicolumn{3}{|l|}{ Ethnicity } \\
\hline White British & 24 & 26 \\
\hline Other white & 2 & 1 \\
\hline Black British & 6 & 7 \\
\hline Other Ethnic Groups & 5 & 3 \\
\hline \multicolumn{3}{|l|}{ Mental Illness Diagnosis } \\
\hline Psychosis & 17 & 15 \\
\hline Schizophrenia & 8 & 9 \\
\hline Bipolar disorder & 7 & 4 \\
\hline Depression & 4 & 6 \\
\hline Other & 1 & 2 \\
\hline \multicolumn{3}{|l|}{ Marital Status } \\
\hline Not Married & 31 & 26 \\
\hline Married & 3 & 4 \\
\hline Other & 3 & 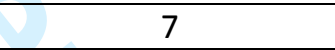 \\
\hline \multicolumn{3}{|c|}{ Admission to Psychiatric Hospital } \\
\hline In the past 2 years & 16 & 20 \\
\hline More than 2 years ago & 9 & 5 \\
\hline Never admitted & 12 & 12 \\
\hline \multicolumn{3}{|l|}{ History of Paid Employment } \\
\hline Yes & 34 & 36 \\
\hline No & 3 & 1 \\
\hline \multicolumn{3}{|l|}{ Currently on Medication } \\
\hline Yes & 30 & 29 \\
\hline No & 7 & 8 \\
\hline
\end{tabular}


Table 3 Mean and standard deviation for secondary outcomes

\begin{tabular}{|c|c|c|c|c|c|c|c|}
\hline Measure & $\begin{array}{l}\text { Treatment } \\
\text { group }\end{array}$ & $\mathrm{N}$ & $\begin{array}{l}\text { Baseline } \\
\text { Mean (S.D) }\end{array}$ & $\mathrm{N}$ & $\begin{array}{l}6 \text { months } \\
\text { Mean (S.D) }\end{array}$ & $\mathrm{N}$ & $\begin{array}{l}12 \text { months } \\
\text { Mean (S.D) }\end{array}$ \\
\hline \multirow{2}{*}{$\begin{array}{c}\text { EQ-5D Index } \\
\text { value }\end{array}$} & IPS only & 37 & $.85(.11)$ & 26 & $.88(.11)$ & 20 & $.90(.11)$ \\
\hline & Intervention & 37 & $.85(.12)$ & 26 & $.88(.10)$ & 22 & $.86(.12)$ \\
\hline EQ-5D & IPS only & 37 & $69.32(20.29)$ & 26 & $76.19(15.83)$ & 20 & $75.10(15.20)$ \\
\hline Health state & Intervention & 37 & 63.51 (23.59) & 26 & $65.08(19.33)$ & 22 & $67.50(17.84)$ \\
\hline \multirow[t]{2}{*}{ Stigma } & IPS only & 37 & $59.46(13.32)$ & 26 & $58.77(10.60)$ & 20 & 59.55 (10.91) \\
\hline & Intervention & 37 & $62.14(12.13)$ & 26 & $59.54(11.60)$ & 22 & 62.95 (14.36) \\
\hline \multirow[t]{2}{*}{ Self-esteem } & IPS only & 37 & $27.95(6.24)$ & 26 & $28.42(5.71)$ & 20 & $28.90(6.86)$ \\
\hline & Intervention & 37 & $27.08(5.90)$ & 26 & $26.77(6.64)$ & 22 & $27.36(6.28)$ \\
\hline \multirow{2}{*}{$\begin{array}{c}\text { SF-12v2 } \\
\text { physical } \\
\text { functioning }\end{array}$} & IPS only & 37 & $5.19(1.05)$ & 26 & $5.31(.88)$ & 20 & $5.50(.69)$ \\
\hline & Intervention & 37 & $5.38(.95)$ & 26 & $5.42(.99)$ & 22 & 5.59 (.59) \\
\hline \multirow{2}{*}{$\begin{array}{l}\text { SF-12v2 } \\
\text { physical } \\
\text { activities }\end{array}$} & IPS only & 37 & $7.73(2.12)$ & 26 & 7.54 (2.19) & 20 & 7.65 (1.87) \\
\hline & Intervention & 37 & $8.05(2.03)$ & 26 & $7.88(2.10)$ & 22 & 8.05 (2.17) \\
\hline \multirow{2}{*}{$\begin{array}{c}\text { SF-12v2 Role } \\
\text { Emotional }\end{array}$} & IPS only & 37 & $7.59(2.14)$ & 26 & $7.61(2.00)$ & 20 & $7.85(2.01)$ \\
\hline & Intervention & 37 & $6.67(2.09)$ & 26 & $6.73(2.25)$ & 22 & $6.86(2.08)$ \\
\hline \multirow{2}{*}{$\begin{array}{c}\text { SF-12v2 } \\
\text { mental } \\
\text { health }\end{array}$} & IPS only & 37 & $7.02(1.80)$ & 26 & $7.31(1.78)$ & 20 & $5.50(.69)$ \\
\hline & Intervention & 37 & $6.03(1.74)$ & 26 & $6.27(2.25)$ & 22 & $6.23(2.14)$ \\
\hline \multirow{2}{*}{$\begin{array}{c}\text { SF-12v2 } \\
\text { general } \\
\text { health }\end{array}$} & IPS only & 37 & $2.92(1.04)$ & 26 & $3.23(1.14)$ & 20 & $3.30(.86)$ \\
\hline & Intervention & 37 & $2.73(1.04)$ & 26 & $2.85(.92)$ & 22 & 3.09 (1.06) \\
\hline \multirow{2}{*}{$\begin{array}{l}\text { SF-12v2 } \\
\text { bodily pain }\end{array}$} & IPS only & 37 & $4.16(1.09)$ & 26 & 4.15 (1.29) & 20 & $4.25(.97)$ \\
\hline & Intervention & 37 & $4.49(.96)$ & 26 & $4.58(.76)$ & 22 & $4.45(.80)$ \\
\hline \multirow{2}{*}{$\begin{array}{l}\text { SF-12v2 } \\
\text { vitality }\end{array}$} & IPS only & 37 & $2.76(.95)$ & 26 & $3.11(1.03)$ & 20 & $3.10(1.29)$ \\
\hline & Intervention & 37 & $2.92(1.16)$ & 26 & $2.65(1.05)$ & 22 & $2.64(.95)$ \\
\hline \multirow[t]{2}{*}{ DEX } & IPS only & 30 & $25.13(13.68)$ & 20 & $22(11.40)$ & 15 & $27.53(14.13)$ \\
\hline & Intervention & 28 & $25.25(14.22)$ & 19 & $24.37(11.62)$ & 15 & 21.33 (10.09) \\
\hline \multirow[t]{2}{*}{ FNE } & IPS only & 30 & $35.43(8.68)$ & 20 & $34.15(10.46)$ & 15 & $34.93(9.56)$ \\
\hline & Intervention & 28 & $36.75(7.05)$ & 19 & 34.10 (9.64) & 15 & 36 (9.69) \\
\hline \multirow[t]{2}{*}{ SPSI } & IPS only & 30 & $11.77(3.67)$ & 19 & $12.20(3.57)$ & 12 & $13.01(2.72)$ \\
\hline & Intervention & 28 & $11.72(3.26)$ & 18 & $12.05(2.90)$ & 15 & $11.30(4.25)$ \\
\hline
\end{tabular}


Table 4: Means of costs and work hours by intervention at baseline ( 3 months before baseline) and over the year post-baseline.ł

\begin{tabular}{|c|c|c|c|c|c|c|c|c|c|c|}
\hline \multirow{3}{*}{ Variable } & \multicolumn{4}{|c|}{ Baseline } & \multicolumn{6}{|c|}{$0-12 \mathrm{Mt}$} \\
\hline & \multicolumn{2}{|c|}{$\begin{array}{l}\text { No intervention } \\
(n=37)\end{array}$} & \multicolumn{3}{|c|}{$\begin{array}{l}\text { Intervention } \\
(\mathrm{n} \|=36)\end{array}$} & \multicolumn{2}{|c|}{$\begin{array}{l}\text { No intervention } \\
(n=29)\end{array}$} & \multicolumn{3}{|c|}{$\begin{array}{l}\text { Intervention } \\
(n=31)\end{array}$} \\
\hline & Mean & SD. & Mean & SD. & P_value\# & Mean & $\begin{array}{l}\text { Std. } \\
\text { Dev. }\end{array}$ & Mean & SD. & P_value\# \\
\hline Paid work (hours/week) & 0.3 & 1.3 & 1.0 & 4.8 & 0.933 & 2.1 & 3.8 & 3.7 & 7.9 & 0.681 \\
\hline \multicolumn{11}{|l|}{ Cost (£) } \\
\hline GP & 320.0 & 410.0 & 195.3 & 318.0 & 0.195 & 181.3 & 155.8 & 94.5 & 102.9 & 0.0249 \\
\hline Dentist & 17.9 & 29.9 & 18.4 & 49.2 & 0.494 & 26.0 & 33.0 & 24.5 & 48.9 & 0.493 \\
\hline Optician & 1.2 & 4.1 & 0.4 & 2.5 & 0.32 & 1.6 & 2.6 & 1.1 & 2.4 & 0.365 \\
\hline Chiropodist & 0.0 & 0.0 & 2.5 & 15.0 & 0.311 & 0.0 & 0.0 & 0.7 & 3.0 & 0.168 \\
\hline Practice Nurse & 37.1 & 83.1 & 22.5 & 69.1 & 0.279 & 34.9 & 51.1 & 7.4 & 11.9 & 0.0066 \\
\hline Other & 1.3 & 8.0 & 2.7 & 11.3 & 0.542 & 7.9 & 16.6 & 4.4 & 17.7 & 0.241 \\
\hline Hospital Overnight stay & $1,552.0$ & $6,922.0$ & 992.9 & $4,011.0$ & 0.697 & 252.6 & $1,073.0$ & 628.5 & $2,087.0$ & 0.443 \\
\hline Outpatient Appointment & 362.1 & 520.4 & 341.2 & 485.5 & 0.757 & 245.7 & 195.1 & 298.4 & 252.2 & 0.556 \\
\hline A\&E Dept & 3.5 & 10.1 & 2.7 & 11.8 & 0.444 & 2.2 & 6.4 & 3.4 & 7.5 & 0.538 \\
\hline $\mathrm{CCO}$ & 442.7 & 280.7 & 545.3 & 338.5 & 0.154 & 273.9 & 260.2 & 304.6 & 244.6 & 0.548 \\
\hline Peer & 2.7 & 12.8 & 2.1 & 10.4 & 0.659 & 1.0 & 3.8 & 1.5 & 6.2 & 0.477 \\
\hline Psychiatrist & 0.0 & 0.0 & 8.9 & 53.2 & 0.311 & 22.0 & 73.5 & 7.7 & 24.0 & 0.865 \\
\hline Psychologist & 0.0 & 0.0 & 34.0 & 163.8 & 0.149 & 41.0 & 138.8 & 87.7 & 270.4 & 0.97 \\
\hline CPN & 11.8 & 71.6 & 20.5 & 71.3 & 0.0953 & 15.6 & 57.3 & 25.1 & 76.7 & 0.405 \\
\hline Social worker & 54.8 & 333.4 & 0.0 & 0.0 & 0.324 & 0.0 & 0.0 & 5.0 & 28.0 & 0.333 \\
\hline OT & 7.3 & 35.6 & 3.3 & 20.0 & 0.575 & 5.4 & 20.3 & 5.7 & 24.4 & 0.477 \\
\hline CMHT or EIP: Other & 1.0 & 6.2 & 2.1 & 12.7 & 0.969 & 1.0 & 5.3 & 0.0 & 0.0 & 0.301 \\
\hline SS: Other & 42.8 & 260.4 & 0.0 & 0.0 & 0.324 & 0.0 & 0.0 & 6.4 & 35.6 & 0.333 \\
\hline Total cost without IPS & $2,858.0$ & $6,909.0$ & $2,195.0$ & $4,015.0$ & 0.834 & $1,112.2$ & $1,306.0$ & $1,507.0$ & $2,114.0$ & 0.739 \\
\hline Total cost without IPS, & $2,858.0$ & $6,909.0$ & $2,236.8$ & $4,065.8$ & & $1,112.2$ & $1,306.0$ & $1,199.7$ & $1,264.4$ & \\
\hline
\end{tabular}




\begin{tabular}{llcccccccccc}
\hline excluding participant 1034§ & & & & 0.915 & & & 0.904 \\
\hline Employment_Specialist & 119.1 & 508.9 & 83.8 & 400.5 & 0.438 & 768.3 & 757.7 & 741.2 & 733.6 & 0.882 \\
\hline Total cost with IPS & $2,978.0$ & $6,884.0$ & $2,279.0$ & $3,998.0$ & 0.808 & $1,880.0$ & $1,387.0$ & $2,248.0$ & $2,030.0$ & 0.559 \\
\hline Intervention & & & & & 0.0 & 0.0 & $136.0^{*}$ & 87.2 & --- \\
\hline Total cost with intervention & & & & & & $1,880.0$ & $1,387.0$ & $2,397.0$ & $2,032.0$ & 0.290 \\
\hline
\end{tabular}

$\ddagger$ Observed means for baseline, and prorated means over the period 0-12 months. All values represent average costs over a 3-month period. $\dagger \mathrm{N}=60$. 0 to 12 month cost calculations excluded those who had only baseline data but without any follow-ups.

TI One participant (1004) was excluded who had 40 hours/week paid work throughout the observation period, including pre-baseline.

${ }^{*} \mathrm{~N}=36$, but 5 participants $(1070,1009,1060,1066,1071)$ did not have any follow-ups. Two of these got intervention sessions $(1060: 2,1071: 6)$. Those 5 participants are excluded from the total cost calculations.

\# From Mann-Whitney Test

$\S$ This outlier participant from the intervention group was hospitalized for 70 days during the post-baseline period. 


\section{Enrollment}

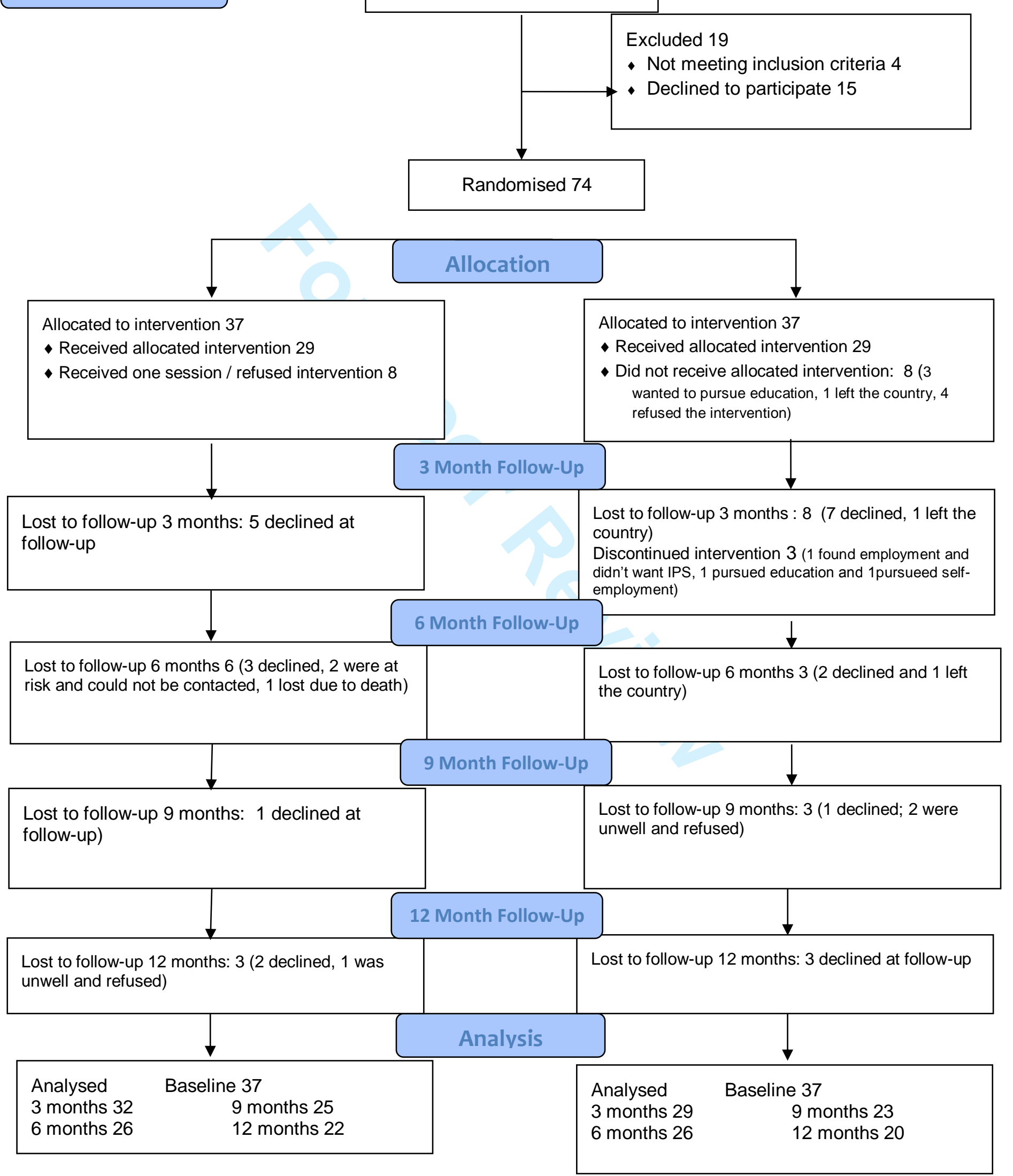

\section{IPS Study Consort Diagram}

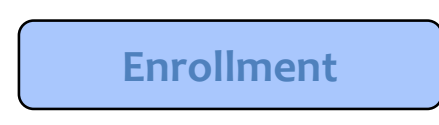

\section{Assessed for eligibility 93}

\section{Excluded 19}

- Not meeting inclusion criteria 4

- Declined to participate 15
Allocated to intervention 37

- Received allocated intervention 29

- Received one session / refused intervention 8

Lost to follow-up 3 months: 5 declined at follow-up
Allocated to intervention 37

- Received allocated intervention 29

Did not receive allocated intervention: 8 (3 wanted to pursue education, 1 left the country, 4 refused the intervention)
Lost to follow-up 3 months : 8 (7 declined, 1 left the didn't want IPS, 1 pursued education and 1pursueed selfemployment)

Lost to follow-up 6 months 3 ( 2 declined and 1 left the country)

Lost to follow-up 9 months: 3 (1 declined; 2 were Lost to follow-up 9 months: 1 declined at ollow-up) Lost to follow-up 6 months 6 ( 3 declined, 2 were at risk and could not be contacted, 1 lost due to death)

Lost to follow-up 12 months: 3 (2 declined, 1 was unwell and refused)

\section{9 months 23}

12 months 20 
Figure 2: Box plots of average paid hours per week in 0-12 month period, and average improvement in paid hours per week from baseline to 0-12 month, by intervention group ( $N=60$ )
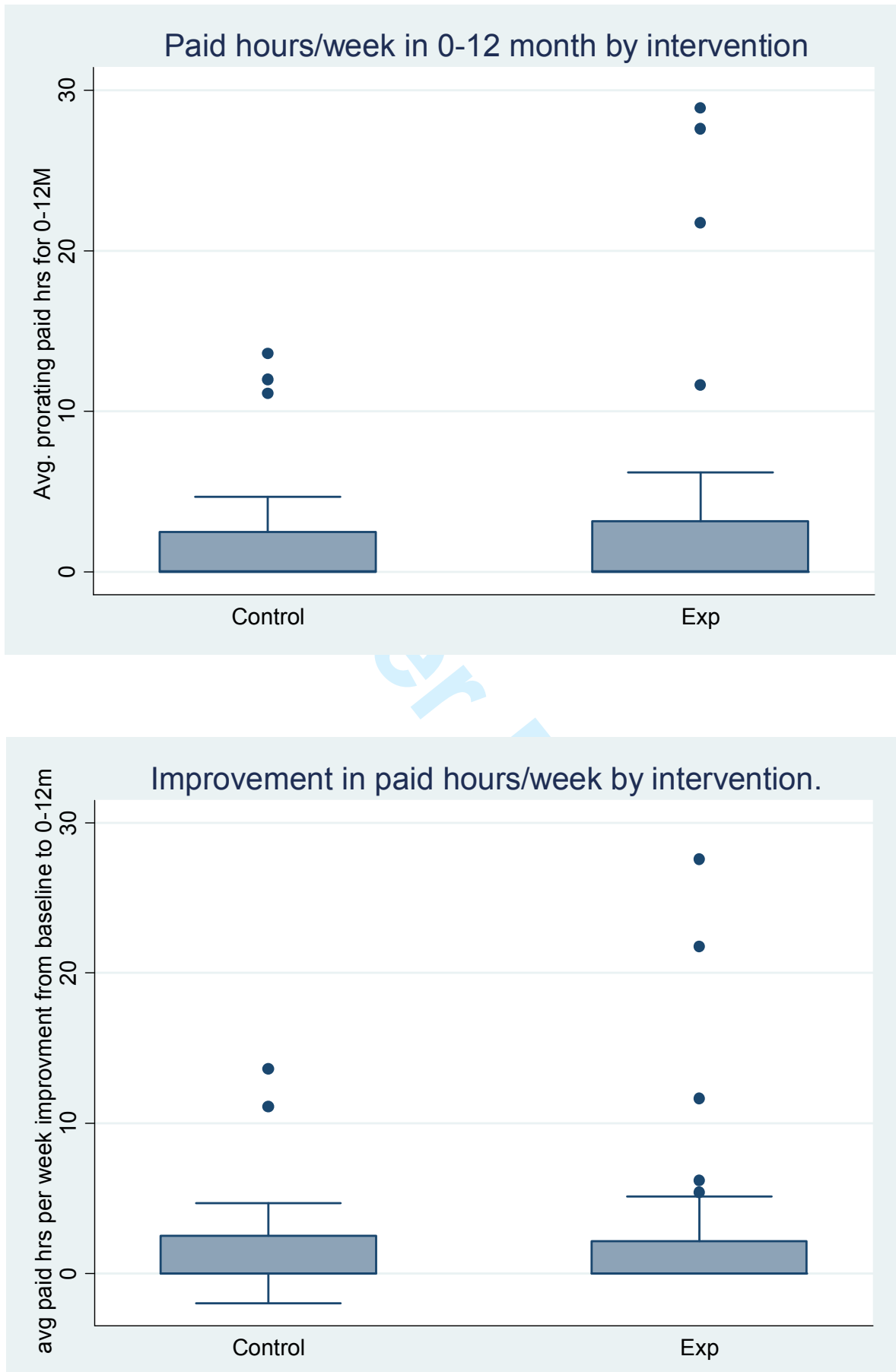
Figure 3a: Average paid hours per week during the 0-12 month period vs. number of work-focused psychological intervention sessions received (Intervention group only, $\mathrm{N}=31$ )

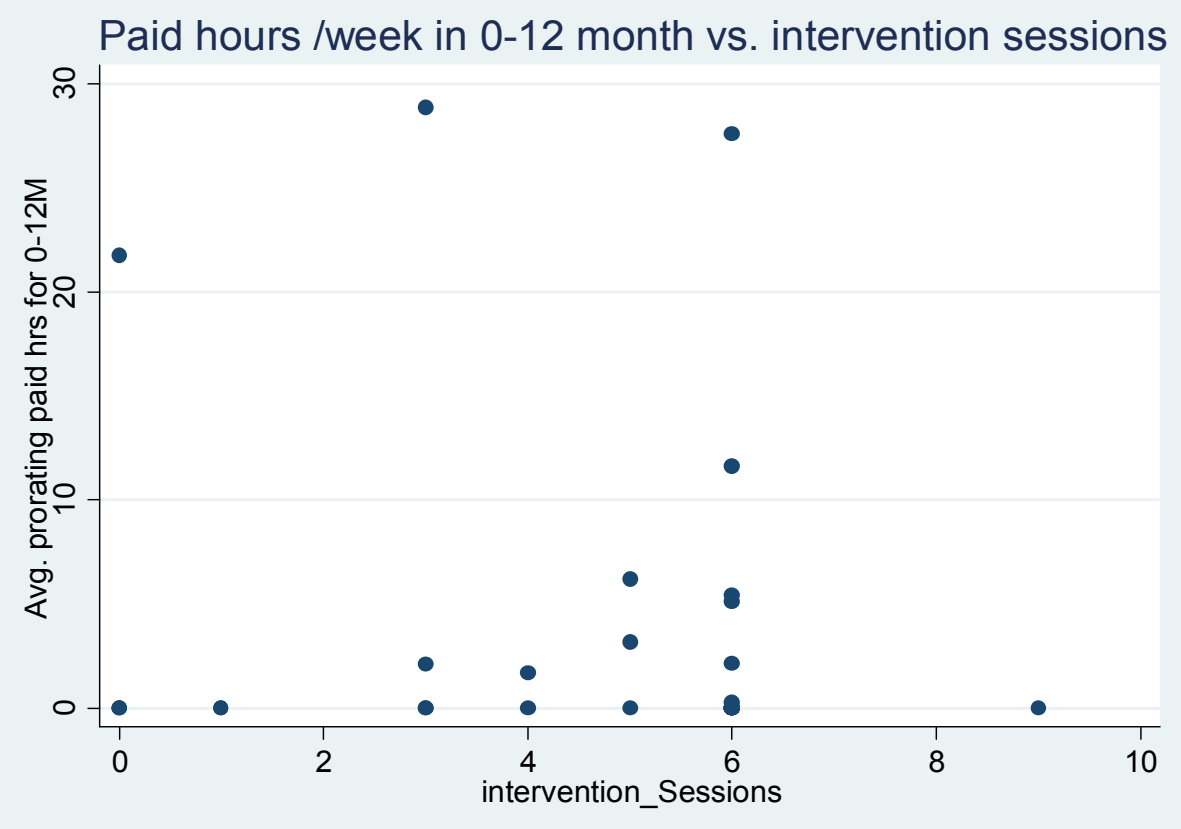

Figure 3b : Improvement in average paid hours per week vs. number of work-focused psychological intervention sessions received (Intervention group only, $\mathrm{N}=31$ ).

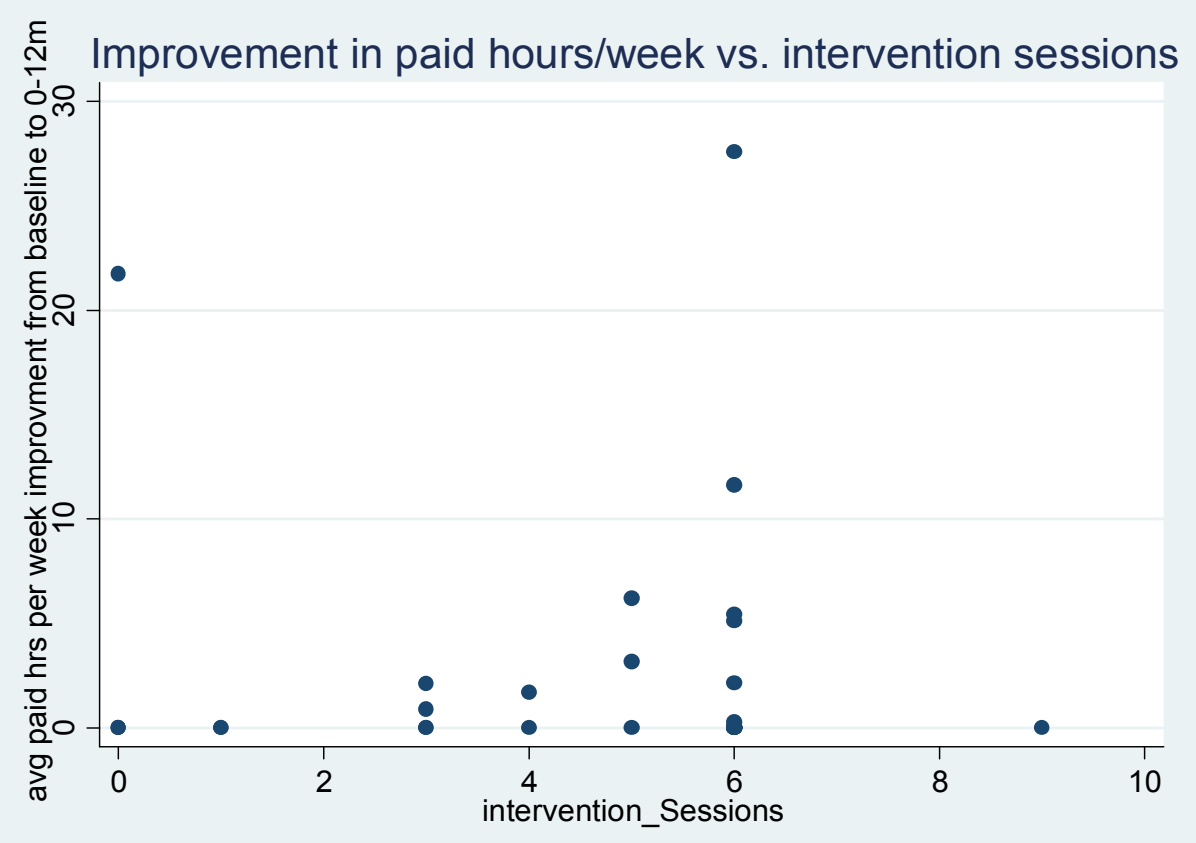


1 Table A.1. Unit costs and their sources ${ }^{1}$

2

\begin{tabular}{|c|c|c|}
\hline Variables & Unit cost & Notes \\
\hline GP & f 185.00 & $\begin{array}{l}\text { "10.8b General Practitioner - unit costs" Hour/minute of patient contact: } \\
\text { average clinic visit time } 17.2 \text { minutes } \\
\text { Includes direct care staff costs (practice nurses) } \\
\text { Excludes qualification costs. }\end{array}$ \\
\hline Dentist & f 66.38 & $\begin{array}{l}\text { Average of lowest (£33) and highest quartile (£72) costs "per attendance" of } \\
\text { Community Dental Services (source PSSRU 2005). Adjusted for } 2012 \text { inflation } \\
\text { (average } 3.4 \% \text { per year, online Bank of England calculator) }\end{array}$ \\
\hline Optician & f 14.90 & $\begin{array}{l}\text { Average NHS voucher expenditure on sight tests. From "General Ophthalmic } \\
\text { Services: Activity Statistics for England, year ending } 31 \text { March } 2012 " .(99.8 \% \text { of } \\
\text { NHS sight tests performed by optometrists, not ophthalologists) }\end{array}$ \\
\hline Chiropodist & f 30.00 & \\
\hline PracticeNurse & f 45.00 & $\begin{array}{l}\text { "10.6 Nurse (GP practice)" } \\
\text { Per hour of face to face contact } \\
\text { Excludes qualification costs } \\
\text { Duration of contacts: } 15.5 \text { min (per surgery consultation) }\end{array}$ \\
\hline Other & f 48.5 & This type of "Other" response was Average of unit cost for a CPN and for an OT. \\
\hline $\begin{array}{l}\text { Hospital_Overnightst } \\
\text { ay }\end{array}$ & $f 586.00$ & $\begin{array}{l}\text { "7.1 NHS reference costs for hospital services - } \\
\text { Non-elective inpatient stays (short stays)": }\end{array}$ \\
\hline Outpatient_App & $f 319.00$ & $\begin{array}{l}15.7 \text { Consultant: Psychiatrist } \\
\text { Per face to face contact } \\
\text { Excludes qualification costs }\end{array}$ \\
\hline AandE_Dept & $£ 32.00$ & $\begin{array}{l}\text { 7.1 NHS reference costs for hospital services - } \\
\text { Walk in services leading to admitted }\end{array}$ \\
\hline $\mathrm{CCO}$ & f 67.00 & $\begin{array}{l}10.2 \text { Nurse (Mental Health) } \\
\text { Per hour of face to face contact } \\
\text { Excludes qualification costs }\end{array}$ \\
\hline Peer & $f 6.19$ & 2012 UK minimum wage \\
\hline Psychiatrist & $f 319.00$ & $\begin{array}{l}15.7 \text { Consultant: Psychiatrist } \\
\text { Per face to face contact } \\
\text { Excludes qualification costs }\end{array}$ \\
\hline Psychologist & $\begin{array}{r}f \\
136.00\end{array}$ & $\begin{array}{l}\text { 9.5 Clinical Psychologist } \\
\text { Per hour of client contact }\end{array}$ \\
\hline CPN & $f 67.00$ & $\begin{array}{l}\text { 10.2 Nurse (Mental Health) } \\
\text { Per hour of face to face contact } \\
\text { Excludes qualification costs }\end{array}$ \\
\hline Social worker & $f 156.00$ & $\begin{array}{l}11.2 \text { Social worker (adult services) } \\
\text { Per hour of face to face contact } \\
\text { Excludes qualification costs }\end{array}$ \\
\hline OT & $f 30.00$ & $\begin{array}{l}9.2 \text { NHS Community Occupational Therapist } \\
\text { Includes qualification costs }\end{array}$ \\
\hline CMHTorEIP_Other & $f 38.00$ & $\begin{array}{l}\text { 12.2 Community mental health team for adults with mental health problems } \\
\text { Per hour per team member }\end{array}$ \\
\hline
\end{tabular}




\begin{tabular}{|c|c|c|}
\hline $\begin{array}{l}\text { Employment } \\
\text { Specialist }\end{array}$ & $f 232.00$ & $\begin{array}{l}\text { We estimated } £ 61,039 \text { as the annual wage of an employment specialist, with } \\
\text { oncosts and overhead included. In total, } 8.6 \text { full-time equivalent employment } \\
\text { specialists provided } 2,270 \text { contacts, for a cost per contact of } 8.6 \times f 61,039=f \\
524,935 / 2,270=£ 232 \text {. }\end{array}$ \\
\hline SS_CCO & $£ 67.00$ & $\begin{array}{l}\text { 10.2 Nurse (Mental Health) } \\
\text { Per hour of face to face contact } \\
\text { Excludes qualification costs }\end{array}$ \\
\hline Homecare & f 23.00 & $\begin{array}{l}11.5 \text { Home care worker. } \\
\text { Based on the price multipliers for the independent sector provided for social } \\
\text { services : } \\
\text { Face to face per hour (weekday) }\end{array}$ \\
\hline SS_Other & $\begin{array}{r}f \\
156.00\end{array}$ & Unit cost for a social worker visit \\
\hline $\begin{array}{l}\text { Intervention } \\
\text { Psychologist }\end{array}$ & $f 136.00$ & $\begin{array}{l}\text { 9.5 Clinical Psychologist } \\
\text { Per hour of client contact }\end{array}$ \\
\hline
\end{tabular}

4 Notes:

$5 \quad{ }^{1}$ Based on the most recently available PSSRU unit costs (2012).

$6 \quad{ }^{2}$ This is an approximate number that may be revised for the final report. 


\section{Responses to comments IPS paper September 252015}

1 In terms of its relevance to occupational therapy, there is an important point missing from the key message about occupational therapists' role in the effective delivery of IPS as well as in the enhancement to IPS.

2 The referencing to the IPS literature is not up to date and in parts of the manuscript is actually incorrect or confusing

3 The fidelity of implementation to IPS needs reporting, so that its contribution to the outcomes obtained can be better understood and discussed
See new opening sentence and paragraph added to the discussion.

Unfortunately, it is difficult to go into this in depth but we think that by referencing Arbesman \& Logsdon (2011) and Waghorn (2009) we have indicated the additional body of literature relevant to OTs.

Newer citations added: Kinoshita et al., 2013, Marshall et al., 2014. Drake \& Bond, 2014. Again, lack of space means these are indicative of a wider body of work.

The following has been inserted: "The fidelity of the IPS service input for the study was measured in October, 2010, at the start of recruitment, by an independent team wo visited the site, following the 25-point Fidelity Scale published online as IPS Resources for Trainers and Fidelity Reviewers (IPS Dartmouth Supported Employment Cente, 2015). The preliminary score was 63 'not IPS' because all the community mental health teams had been merged into one, creating a highly diluted IPS service, reviewers commented that "...there will need to be structural changes to the way the service is managed if it is to deliver the outcomes expected of a high fidelity service". To achieve a more rigorous model of IPS, after recruiting 17 participants, the focus of the study shifted to a team dealing with early psychosis, where the remaining 57 participants were recruited up to June, 2012. This team was smaller, working with a younger clientele and more amenable to implementing IPS fully. The next external fidelity review, in February 2012, scored the service fidelity as 'good' with 101 points."

4 The primary outcome is not clear, and a definition of paid We have added the phrase 'in the open labour market' to our definition of the primary outcome. See 13 below for clarification of primary outcome. employment is needed.

5 Throughout the document difference phrases are used to 


\begin{tabular}{|c|c|c|}
\hline & describe the intervention. & \\
\hline 6 & $\begin{array}{l}\text { Following these changes, I recommend the abstract and } \\
\text { conclusions are revised accordingly. }\end{array}$ & Done \\
\hline \multirow[t]{3}{*}{7} & $\begin{array}{l}\text { More up to date references can be used for the opening } \\
\text { statement about the evidence base for IPS - }\end{array}$ & See 2 above \\
\hline & +2 & \\
\hline & Methods & \\
\hline \multirow[t]{2}{*}{8} & $\begin{array}{l}\text { The authors should report here how the CONSORT methods } \\
\text { for conducting RCTs were followed. }\end{array}$ & $\begin{array}{l}\text { Consort diagram was inadvertently omitted from the submission and has } \\
\text { been reintegrated. }\end{array}$ \\
\hline & & 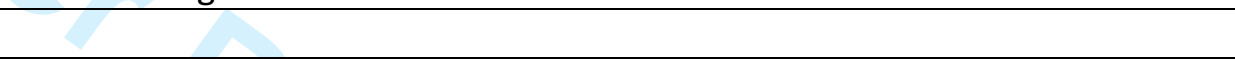 \\
\hline 10 & $\begin{array}{l}\text { Fidelity measurement - the reference used is Bond et al, } \\
1997 \text { - this is the IPS-15 scale. Was this scale used, or was } \\
\text { the IPS- } 25 \text { used? Please clarify, and also outline - how } \\
\text { fidelity was measured (internal review, research team } \\
\text { review or an independent review and the process used }\end{array}$ & $\begin{array}{l}\text { The paragraph now reads: "The key objectives and methods of working within an } \\
\text { IPS model are well established (Dartmouth IPS Supported Employment Center, } \\
\text { 2012). Broadly, this entails intensive, individualised, employment-focussed advice } \\
\text { and practical support without time limit. The fidelity of the particular IPS service } \\
\text { provided for the study was measured in October, 2010, at the start of }\end{array}$ \\
\hline
\end{tabular}




\begin{tabular}{|c|c|c|}
\hline & $\begin{array}{l}\text { (telephone interviews, on-site for } 2 \text { days?), } \\
\text { what the scores were and which individual items the } \\
\text { program did not score a } 4 \text { or } 5 \text { on. }\end{array}$ & $\begin{array}{l}\text { recruitment, by an independent team who visited the site, following the 25- } \\
\text { point Fidelity Scale published online as IPS Resources for Trainers and Fidelity } \\
\text { Reviewers (IPS Dartmouth Supported Employment Center, 2015). The } \\
\text { preliminary score was 63, 'not IPS', because all the community mental health } \\
\text { teams had been merged into one, creating a highly diluted IPS service, and } \\
\text { reviewers commented that "... there will need to be structural changes to the } \\
\text { way the service is managed if it is to deliver the outcomes expected of a high } \\
\text { fidelity service". Since changing mental health services structures was } \\
\text { beyond the scope of the study, after recruiting } 17 \text { participants, in order to } \\
\text { achieve a more rigorous model of IPS, the focus of recruitment shifted to a } \\
\text { team dealing with early psychosis, where the remaining } 57 \text { participants } \\
\text { joined the study by June, 2012. This team was smaller, working with a } \\
\text { younger clientele and more amenable to implementing IPS fully. The next } \\
\text { external fidelity review, in February 2012, scored the service fidelity as 'good' } \\
\text { with } 101 \text { points. " } \\
\text { In our view giving the detail requested on individual items would not } \\
\text { improve the paper because the ratings were not done by the researchers. } \\
\text { While the global scores serve to describe the IPS available to our } \\
\text { participants, sub-scores would add little information to this paper without a } \\
\text { great deal of contextual detail. It's our considered view that this detail is not } \\
\text { relevant to the paper as an account of a pragmatic trial; the total scores give } \\
\text { sufficient information. Moreover, the sub-scores are data for which the } \\
\text { research team cannot vouch. }\end{array}$ \\
\hline & Work-focussed intervention & \\
\hline 11 & $\begin{array}{l}\text { It is hard to understand if Working Well! is what the work- } \\
\text { focused intervention etc. }\end{array}$ & Please see response to comment 5. \\
\hline 12 & $\begin{array}{l}\text { Finally how was the quality of the psychological intervention } \\
\text { measured? }\end{array}$ & $\begin{array}{l}\text { Added: The intervention was independently evaluated using a qualitative } \\
\text { approach and this is reported in Boycott, Akhtar and Schneider (2015). }\end{array}$ \\
\hline
\end{tabular}




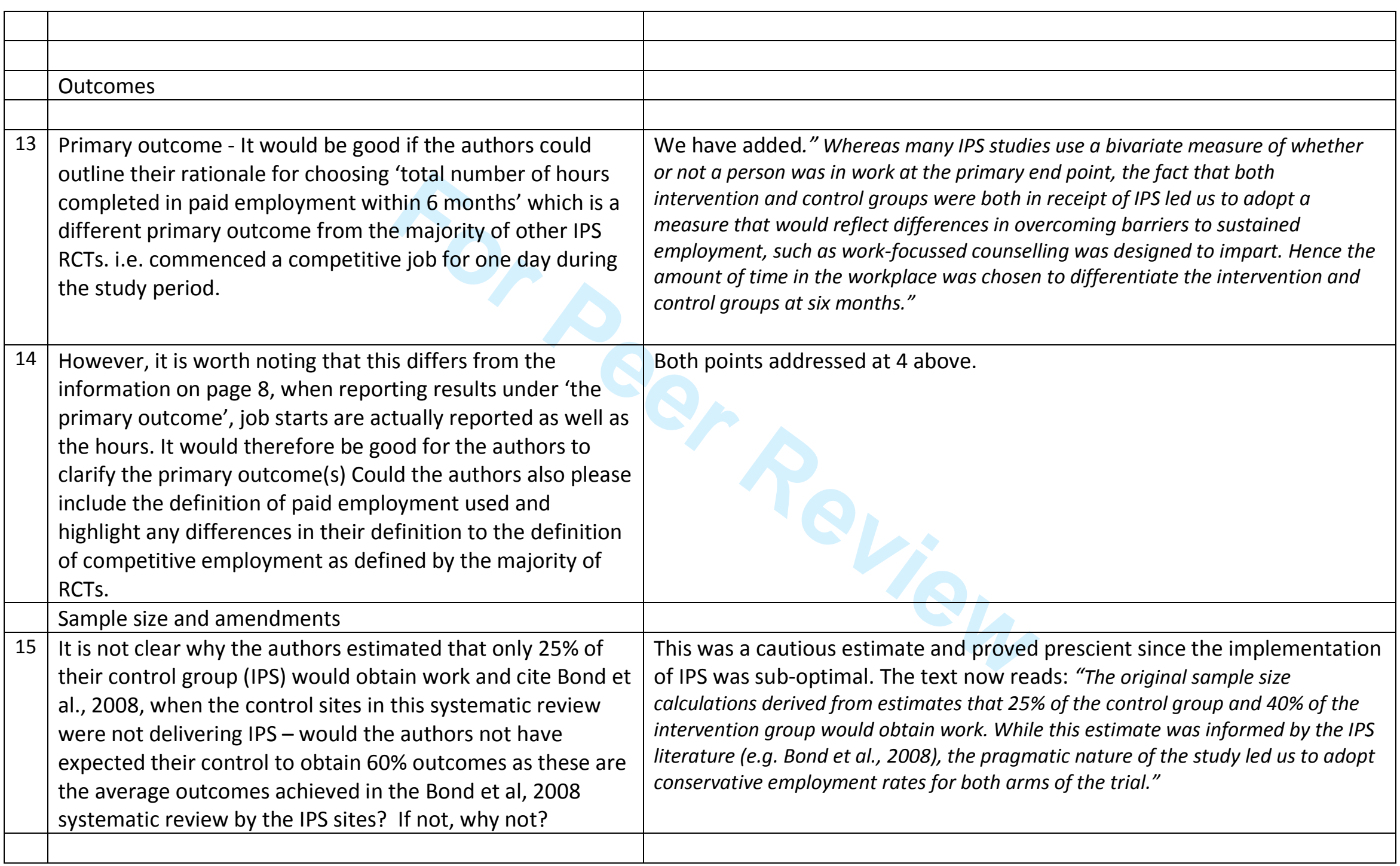




\begin{tabular}{|c|c|c|}
\hline & Limitations & \\
\hline \multirow[t]{4}{*}{16} & $\begin{array}{l}\text { In the discussion on the influence of labour market it would } \\
\text { be worth citing Catty et al, } 2007 \text { (from the EQOLISE trial) } \\
\text { where the specific effect of the local unemployment rate on } \\
\text { employment outcomes were documented. I am not sure the } \\
\text { DWP comparisons are that helpful, after all a } 7 \% \text { increase in } \\
\text { outcomes is small given the intensive employment program } \\
\text { offered in this trial. If the Work Programme data is kept in, } \\
\text { then it will be important to explain briefly what 'the Work } \\
\text { Programme offers' and how this compares to IPS. }\end{array}$ & $\begin{array}{l}\text { The same study has been cited as Knapp et al. in terms of its cost- } \\
\text { effectiveness. The EQOLISE trial was a cross-national comparison, with } \\
\text { widely varying labour markets and social security systems. We consider that } \\
\text { UK-specific data are a more relevant comparator in the context of our small, } \\
\text { local study. This is our justification for the DWP comparison. }\end{array}$ \\
\hline & & \\
\hline & Conclusion & 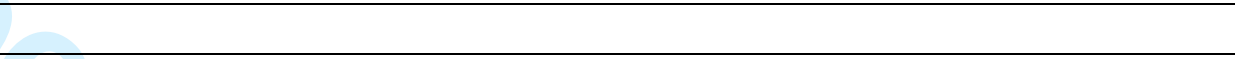 \\
\hline & & 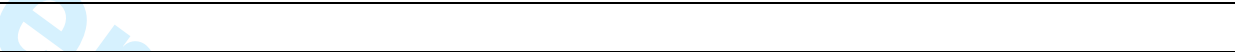 \\
\hline \multirow[t]{7}{*}{17} & $\begin{array}{l}\text { The hypothesis stated here is different from that outlined at } \\
\text { the start of the study. The term CBT is used, whereas in the } \\
\text { introduction 'work-focused intervention' is used. }\end{array}$ & Corrected \\
\hline & What the study has added - Again the term CBT is used. & Corrected \\
\hline & & 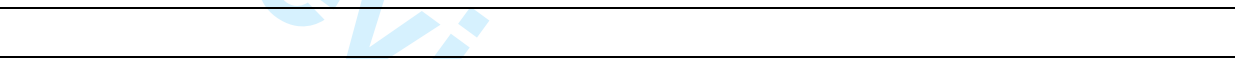 \\
\hline & & \\
\hline & Reviewer: 2 & \\
\hline & & 18 \\
\hline & Comments to the Author & 8 \\
\hline 18 & $\begin{array}{l}\text { 1. The intervention has to be defined and better } \\
\text { described. Authors suggest to consult the following paper } \\
\text { for obtaining more information on the intervention: Boycott } \\
\mathrm{N} \text {, Schneider J, McMurran M (2012) Interventions to } \\
\text { Enhance the Effectiveness of Individual Placement and } \\
\text { Support: A Rapid Evidence Assessment, Rehabilitation }\end{array}$ & $\begin{array}{l}\text { This now reads: "This intervention was developed and piloted as part of the } \\
\text { present study; informed by previous studies (Coldham et al., 2002; Rose and Perz, } \\
\text { 2005; Boycott et al., 2012) and based on generic psychological practice, including } \\
\text { goal-based motivational procedures and cognitive behaviour therapy (CBT). This } \\
\text { work-focussed counselling intervention was designed to enhance the impact of IPS } \\
\text { by addressing common obstacles to employment which are not directly due to }\end{array}$ \\
\hline
\end{tabular}




\begin{tabular}{|c|c|c|}
\hline & $\begin{array}{l}\text { Research and Practice Article ID 382420, } 8 \\
\text { pages, doi:10.1155/2012/382420. However, this paper } \\
\text { presents different types of interventions (e.g., skills training, } \\
\text { cognitive remediation) and consequently, the reader does } \\
\text { not know which intervention has been retained for the } \\
\text { present manuscript. Has the content been developed from } \\
\text { these interventions? On reading, the content appears } \\
\text { related to psycho-education and not CBT per se. Please give } \\
\text { more details on this intervention. }\end{array}$ & $\begin{array}{l}\text { symptomatology (e.g. hallucinations) and not normally the concern of the clinical } \\
\text { team (e.g. medication adherence). An intervention manual based on a life goals } \\
\text { and a problem solving approach was developed and supplemented by self-help } \\
\text { materials. It was delivered by a trained psychologist (NB) with individual } \\
\text { participants. Each received a booklet ('Working Well!') containing information } \\
\text { about six topics (anxiety, depression, self-esteem, memory/concentration, stigma } \\
\text { and getting on with others) and was asked to choose a maximum of four topics to } \\
\text { discuss with the psychologist over up to } 6 \text { sessions lasting about an hour, mostly } \\
\text { taking place in the participant's home. The intervention was independently } \\
\text { evaluated using a qualitative approach and this is reported in Boycott, Akhtar and } \\
\text { Schneider (2015)." }\end{array}$ \\
\hline 19 & $\begin{array}{l}\text { 2. In link with the previous point, results from the pilot } \\
\text { project are non-significant and I am wondering if it is due to } \\
\text { the content of the intervention or the sample size. Two } \\
\text { suggestions: to better define the intervention (i.e. } \\
\text { components and goals) as mentioned above and comment } \\
\text { on potential gaps, or recruit more participants for the study } \\
\text { or both suggestions. }\end{array}$ & This is discussed in the paper on $\mathrm{p} 12 \mathrm{ff}$ \\
\hline 21 & $\begin{array}{l}\text { 4. I am not convinced when authors mentioned (in the } \\
\text { section entitled: what the study has added) that CBT is } \\
\text { broadly acceptable and feasible as an adjunct intervention } \\
\text { to IPS. Please give more arguments. }\end{array}$ & Corrected \\
\hline 22 & $\begin{array}{l}\text { The cost evaluation requires to be evaluated by an expert } \\
\text { on this domain. }\end{array}$ & This is a comment for the editor. \\
\hline
\end{tabular}




\section{Introduction}

Occupational therapists have always been at the vanguard of innovation and development in promoting employment for people with mental health problems, both in the UK (Rinaldi \& Perkins, 2007) and beyond (Waghorn et al., 2009). The approach called Individual Placement and Support (IPS) has a good evidence base (Burns et al., 2007; Marwaha et al., 2007; Kinoshita et al., 2013, Marshall et al., 2014, Drake \& Bond, 2014) but its implementation is exacting in many ways. For instance, it requires co-location of employment support staff with community mental health staff, and this can present organisational barriers. Also, IPS employment support workers should have caseloads of about 20 , enviably low compared to caseloads of most community mental health team members (Swanson and Becker, 2011, Schneider and Akhtar, 2012). In short, while IPS is increasingly widely-adopted in the UK, it cannot be said to be part of 'standard' mental health services.

\section{Literature review}

There has been a call for a 'more formal evidence base for occupational therapy interventions in the field of supported employment' (Priest and Jones, 2010). Arbesman and Logsdon (2011) reviewed the OT literature on employment support and concluded that IPS had 'strong evidence' in its favour but its outcomes were stronger in combination with cognitive or social skills training. Our earlier review concluded that more evidence was needed concerning the potential to increase the power of IPS by combining it with adjunct interventions (Boycott et al., 2012). There is increasing evidence that on its own IPS results in significant cost offsets by increasing the proportion of clients who work (Bush et al., 2009; Kilian et al., 2011; Perkins et al., 2005; Schneider et al., 2009). In terms of both days worked and whether the individual had worked at least for one day, IPS generated improvements and was cost-saving from the point of view of the health and social care systems (Knapp et al., 2013). However a key question about enhancing IPS is the whether the additional cost of the enhancement is warranted by the benefits.

The present study aimed therefore to test the hypothesis that work-focussed counselling as an adjunct to IPS will prove more successful in helping people with schizophrenia and 
related disorders into paid employment than IPS alone. The design was a two-arm, parallel, randomised controlled trial of enhanced IPS versus IPS alone, with a costeffectiveness arm added because of previous findings cited above. By taking a pragmatic and exploratory approach we sought also to investigated whether participation might affect engagement with education, training and volunteering, as well as the implications of the findings for the wider implementation of IPS. Here, we report on the results of the main outcome, paid employment in the open labour market, and on the take-up of education, training and volunteering, together with the results of the costs analysis. The implications for the wider implementation and evaluation of IPS are also considered in our discussion below.

\section{Method}

Setting

This context for this study was a Collaborative for Leadership in Applied Health Research and Care (CLAHRC), focusing on putting evidence into practice (Rowley et al., 2012). The study was undertaken in one mental health provider, Nottinghamshire Healthcare NHS Trust. A preliminary phase put in place a fully-operational IPS service through the appointment of an IPS Development Manager for two years (Schneider and Akhtar, 2012). Following this period, the present study recruited participants from the caseloads of one Community Mental Health team ('Rehabilitation and Recovery') and one Early Intervention in Psychosis (EIP) team based within Nottinghamshire Healthcare NHS Trust (NHCT) in 20102012. A positive ethical opinion was granted by Derbyshire Research Ethics Committee (ISRCTN18240558).

\section{Inclusion and Exclusion Criteria}

People who consented to participate were eligible if they were aged 18-60 and on the caseload of the Rehabilitation and Recovery or EIP teams. We excluded anyone who was an inpatient at the time of the invitation to participate, people currently in work or in education and those not wishing to work, anyone who was unable to give informed consent, and anyone who was already receiving cognitive behaviour therapy (CBT). Provision was made to employ interpreters but none required this support. The initial approach to service 
users was made by their usual care co-ordinators and interested parties responded directly to the research team or via the care co-ordinator.

\section{Randomisation}

The researcher, after gaining informed consent, entered participants' details onto a webbased randomisation system. Group allocation was sent directly via encrypted email to an administrator, who forwarded details to the psychologist delivering the intervention. Details of allocation were kept by the administrator and psychologist in password-protected files. The psychologist made contact with participants in the intervention arm to inform them of their allocation. The researcher responsible for assessing participants at baseline and follow-up was thus 'blind' to allocation until all data collection had been completed.

\section{Interventions}

Treatment as usual - IPS

On enrolment to the study participants were assigned to an Employment Specialist (an IPStrained worker) who met with them at a mutually-agreed location (often the participant's home) to produce an action plan for employment. Participants continued to meet with their Employment Specialist as often as they wished, in keeping with the responsive ethos of the intervention. The key objectives and methods of working within an IPS model are well established (Dartmouth IPS Supported Employment Center, 2012). Broadly, this entails intensive, individualised, employment-focussed advice and practical support without time limit. The fidelity of the particular IPS service provided for the study was measured in October, 2010, at the start of recruitment, by an independent team who visited the site, following the 25-point Fidelity Scale published online as IPS Resources for Trainers and Fidelity Reviewers (IPS Dartmouth Supported Employment Center, 2015). The preliminary score was 63, 'not IPS', because all the community mental health teams had been merged into one, creating a highly diluted IPS service, and reviewers commented that "...there will need to be structural changes to the way the service is managed if it is to deliver the outcomes expected of a high fidelity service". Since changing mental health services structures was beyond the scope of the study, after recruiting 17 participants, in order to achieve a more rigorous model of IPS, the focus of recruitment shifted to a team dealing 
with early psychosis, where the remaining 57 participants joined the study by June, 2012 . This team was smaller, working with a younger clientele and more amenable to implementing IPS fully. The next external fidelity review, in February 2012, scored the service fidelity as 'good' with 101 points.

\section{Work-Focussed Counselling Intervention}

In addition to IPS as described above, participants randomised to the intervention arm of the trial were offered 3-6 sessions of work-focussed counselling delivered by a psychologist. This intervention was developed and piloted as part of the present study; informed by previous studies (Coldham et al., 2002; Rose and Perz, 2005; Boycott et al., 2012) and based on generic psychological practice, including goal-based motivational procedures and cognitive behaviour therapy (CBT). This work-focussed counselling intervention was designed to enhance the impact of IPS by addressing common obstacles to employment which are not directly due to symptomatology (e.g. hallucinations) and not normally the concern of the clinical team (e.g. medication adherence). An intervention manual based on a life goals and a problem solving approach was developed and supplemented by self-help materials. It was delivered by a trained psychologist (NB) with individual participants. Each received a booklet ('Working Well!') containing information about six topics (anxiety, depression, self-esteem, memory/concentration, stigma and getting on with others) and was asked to choose a maximum of four topics to discuss with the psychologist over up to 6 sessions lasting about an hour, mostly taking place in the participant's home. The intervention was independently evaluated using a qualitative approach and this is reported in Boycott, Akhtar and Schneider (2015).

\section{Outcomes}

\section{Primary}

The main outcome was the total number of hours in paid employment (in the open labour market) 6 months after entering the trial. Whereas many IPS studies use a bivariate measure of whether or not a person was in work at the primary end point, the fact that both intervention and control groups were both in receipt of IPS led us to adopt a measure that would reflect differences in overcoming barriers to sustained employment, such as 
work-focussed counselling was designed to impart. Hence the amount of time in the workplace was chosen to differentiate the intervention and control groups at six months. Secondary

The study was implemented at a time of economic recession in the UK, which seemed likely to adversely affect the job prospects of participants, so vocational activities such as education, training and volunteering were also measured. The questionnaires used are listed in Table 1. They include the Rosenberg Self-Esteem Scale (Rosenberg, 1965), the EQ5D (EuroQOL Group, 1990) and the Client Service Receipt Inventory (Beecham and Knapp, 1992) which yield data required for estimating and comparing costs, and the SF-12 which measures health and wellbeing (Ware et al., 2002). Less widely-used measures were applied to explore the impact on self-assessed barriers to work (Lerner et al., 2004a, 2004b) perceived stigma (Schneider et al., 2011), avoidance of social disapproval (Leary, 1983), social cognition (Burgess et al., 1996) and social problem solving (D'Zurilla et al., 2002).

Table 1 about here

The researcher assessed participants face-to-face at baseline, 6 and 12 months and by telephone at 9 months. Demographic, work and education history and clinical details were gathered at baseline. At baseline, 3, 6, 9 and 12 months, the researcher collected data about working hours, welfare benefits received and services used (excepting the experimental intervention). Secondary outcome measures shown in Table 1 were administered at baseline, 6 and 12 months to both groups. At about 9 months, qualitative interviews were held with an opportunistic sample of 31 individuals, to explore the participants' experience of the intervention, their satisfaction with the process and how it could be improved.

\section{Sample size and amendments}

The original sample size calculations derived from estimates that $25 \%$ of the control group and $40 \%$ of the intervention group would obtain work. While this estimate was informed by the IPS literature (e.g. Bond et al., 2008), the pragmatic nature of the study led us to adopt conservative employment rates for both arms of the trial. For an $80 \%$ power of 
demonstrating this difference $(p<0.05), 165$ participants were required in each arm of the trial. Recruitment during the first 6 months was 17 and it emerged that one Employment Specialist's caseload capacity was constrained by pre-existing clients, while as noted above organisational restructuring made IPS fidelity inadequate. Application was therefore made to the ethics committee for a substantial amendment to enable the study to recruit from an Early Intervention in Psychosis team, while the target sample size was revised downwards to a minimum of 28 per arm on the basis of what would be feasible within the constraints of the funding and remaining time available. The amendment also extended three psychometric measures (DEX, SPSI-R and BFNE, 20-22), which had initially only been used with the intervention group, to be used with all participants. This was to assess any treatment affects, which we expected to be greater in the intervention group. The possible sample size for the DEX, FNE and SPSI was therefore reduced by 17 because these measures were only introduced after that number of participants had been recruited.

\section{Statistical analysis}

The primary analysis was intention-to-treat and included all participants who were randomly assigned to their respective groups (intervention or control), regardless of whether they engaged with IPS/enhanced IPS or not. Participants who were lost to followup were assumed to be not working and the number of hours was recoded as zero.

\section{Costs estimation and analysis}

To estimate costs, we multiplied frequencies obtained by, in most but not all cases, PSSRU unit costs for 2012 (PSSRU, 2013). Details are in the Appendix. For the purpose of examining the distributions of the values, we prorated available data to obtain annualized, and thus comparable, numbers. Having done this, we calculated means by group. We also used box plots to compare the distributions of paid hours post-baseline for the intervention and control groups, as well as improvement in paid hours (adjusting for baseline differences).

Bootstrapping and multiple imputation were used to both estimate the incremental costeffectiveness ratio (ICER), and assess uncertainty in the ICER. We began by obtaining 1000 
sample replicates using bootstrapping. For each sample, we used multiple imputation (with 20 imputed data sets) to calculate a mean cost and mean effect. These were plotted on a cost-effectiveness plane. From the location of the points on the cost-effectiveness plane, a cost-effectiveness acceptability curve was derived. This procedure also is used to compute an ICER and a standard error for the ICER; 'bootstrap' and 'mi' procedures in Stata 13 were used to calculate this.

Finally, we examined bivariately whether there appeared to be an association between paid hours, or improvement in paid hours, on the one hand, and on the other hand, the number of hours of psychological intervention received. If the psychological intervention increased paid hours, one would expect to see a dose-response relationship.

\section{Results}

Seventy four individuals were recruited to the study from August 2010 to June 2012, 37 randomised to each arm. In total, 32 of these individuals (43\%) were lost to follow-up (see Consort diagram). Their destinations up are unknown but in the analysis we assume they were not working.

\section{Adverse events}

One participant committed suicide during the trial, but this was judged to be due to a significant mental health relapse and not related to participation in the study. No other adverse effects were reported.

\section{Attrition}

Attrition analyses were conducted in relation to gender, age, clinical history and the secondary outcome measures. Independent t-tests showed a statistically significant difference for age; individuals who stayed in the study were older with a mean age of 32.23 (s.d. 9.69) as compared to 27.03 (s.d. 9.32) ( $t=-2.33$, $d f=72, p<.05)$. No other differences were found for individuals who stayed in the study in comparison to those who were lost to follow-up at each time-point.

Figure 1 (Consort Diagram) about here 


\section{Demographic and Clinical Characteristics}

Table 2 shows the demographic and clinical characteristics of the entire sample.

Independent t-tests and non-parametric Mann Whitney U-tests were conducted to compare the two groups' demographic and clinical characteristics. No significant differences were found, suggesting that the two groups were equally matched at baseline for age, ethnicity, marital status and clinical history.

Table 2 about here

Primary Outcome

In relation to the primary outcome, hours per week (hpw) of (paid) employment after six months, the mean hpw worked was 3.22 (s.d. 9.53) for the 37 individuals who were part of the control group, and $3.89 \mathrm{hpw}$ (s.d. 10.60) for the 37 individuals who were part of the intervention group. At 12 months the mean number of hours worked by individuals who were part of the control group $(\mathrm{N}=37$ ) was 3.67 (s.d. 7.80) and 7.07 (s.d. 14.09) for individuals who were part of the intervention group $(\mathrm{N}=37)$ (Table 3$)$. Using the MannWhitney $U$ test, no statistically significant difference was found between the intervention and control groups in relation to the main outcome; mean number of hours worked per week at 6 months $(z=0.57, p=0.56)$ and this was also true at 12 months $(z=0.71, p=0.48)$. Twenty five out of 74 people entered employment over the course of the study. Of this number, 12 were working full time, defined as 35-45 hours hpw, 3 worked 20-30 hpw, 6 worked 10-16 hpw and 4 less than $10 \mathrm{hpw}$.

There were no statistically significant differences between the two groups at any time point on the secondary outcome measures.

In terms of voluntary work and education/training, 12 participants started voluntary work and 9 entered education/training during the study. This group comprised 7 individuals from the control group and 5 individuals from the intervention group who were volunteering and 3 individuals from the control group and 6 individuals from the intervention group who were in education/training. There were no statistically significant differences for voluntary work between the two groups $\left(\mathrm{Chi}^{2}=0.39, \mathrm{df}=1, \mathrm{p}=0.53\right.$ ) nor for education/training between the control or intervention group $\left(\mathrm{Chi}^{2}=1.14, \mathrm{df}=1, \mathrm{p}=0.28\right)$. 
Reasons for attrition

The reasons for attrition are shown in the Consort Diagram (Fig 1). These are similar for both arms of the trial: equal numbers people declined IPS with treatment as usual (control), and the work-focussed counselling with IPS (intervention). Thereafter, the loss to study rates are not remarkably different: three people left the country following baseline assessment, all happened to be in the TAU arm of the trial, while one person from the intervention arm sadly died through suicide. Otherwise people were too unwell or declined the follow-up interviews, despite careful steps taken to engage their co-operation; letters were sent to participants who declined, informing them about the importance of staying in the study and their care coordinators were repeatedly contacted to try and re-engage them back into study. Generally, those who left the study were affected by severe mental illness or felt that they had gained little from participation. The people who obtained work remained in contact with the study, with one exception.

\section{Figure 1 about here}

\section{Secondary Outcomes}

Table 4 shows that mean scores for self-esteem, stigma, physical and mental health and for problem-solving measures did not differ significantly between the two study groups. No difference was found at an individual level for most of the secondary outcomes between baseline and 6 months and baseline and 12 months, with three exceptions. Due to the number of t-tests applied, and given the contradictory interpretations of these findings, they may well be due to chance but they are reported here for future reference:

At an individual level, for the entire study sample, repeated measures t-tests indicated significant change in the mean health state score on the EQ-5D between baseline (65.78) and 6 months $(70.63)(t=-1.98, d f=51, p<.05)$ and this was also true comparing baseline (64.95) to 12 months (71.11) $(t=-2.28, d f=41, p<.05)$. The results suggest that individuals perceived their health status to worsen over time.

By contrast, significant difference was found in the vitality scale of the SF-12v2 measure. 'Vitality' measures how much of the time the respondent felt energetic. Vitality scores increased between baseline (2.83) and 12 months (3.19) $(t=-2.35, d f=41, p<.05)$. 
Thirdly, change was found in the brief fear of negative evaluation scale scores between baseline (37.10) and 6 months (34.12) $(t=2.37, d f=38, p<.05)$, suggesting that individuals' fear of negative evaluations significantly decreased between baseline and 6 months.

\section{Additional Analysis}

As an aside from the ITT analysis, if we look post-hoc at the people who took up the opportunity to engage with the psychotherapeutic input, there is an indication that this made a difference. Of the 29 people who took up the experimental intervention, 12 obtained employment (41\%), compared to 13 of the 45 (29\%) who did not receive the experimental intervention ( 37 who were randomised to IPS-only group plus 8 who were randomised to the IPS+ group but did not attend intervention). Although there were no statistically significant differences between groups $\left(\mathrm{Chi}^{2}=0.73, \mathrm{p}=0.39\right)$, for the people who received the experimental intervention, the odds ratio of obtaining employment was 1.74 $(95 \% \mathrm{Cl}=0.65-4.63)$, suggesting a positive effect of receiving intervention.

Furthermore, in terms of retention within the trial and in IPS services, fewer of those who received the work-focussed counselling intervention dropped out than those who had not received the intervention. Nine of the 29 participants who received intervention dropped out of the RCT (31\%), compared with 23 of the 45 participants who received IPS alone (51\%). Again, this difference was not statistically significant $\left(\mathrm{Chi}^{2}=2.14, \mathrm{df}=1, \mathrm{p}=0.14\right)$, but the odds ratio of $0.43(95 \% \mathrm{Cl}=0.16-1.14)$ suggests a positive effect of receiving the intervention.

\section{Costs}

Table 4 provides means and standard deviations of paid hours, use of services, cost subtotals and total costs, by group, at baseline and during the subsequent 12-month time period. The data contained a number of missing values. Some individuals had no data beyond the baseline assessment. These were dropped from the cost-effectiveness analysis. Others had at least data for the 3-month period. All cost values, both pre- and postbaseline, are expressed as over a 3-month period. 
Paid hours appear somewhat higher for the intervention group, both at baseline and during the 12-month, post-intervention period. Also, total costs are somewhat lower for the intervention group pre-baseline, and somewhat higher post-baseline, a difference that arises only partly from the cost of the intervention itself, which averages to $f 136$. More detailed observation of the distribution of resource use and costs indicated that this difference was partly due to one participant assigned to the intervention group, who had an unusually long hospitalization (70 days) towards the end of the one-year post-baseline period. The participant with the next-highest number of days, who was assigned to the control group, had 12 days. No other participant was hospitalized. We removed the outlier from the sample and redid the above calculations as a sensitivity analysis, the results are shown in Table 4. In order to assess the influence of the multiple imputation procedure on the results, we also did the calculations, including the individual with a high number of hospital days, by prorating costs and paid hours rather than by using multiple imputation. It is important to note that in either case the data in Table 4 show no indication of a possible cost offset.

\section{Figures $2 a \& b$ about there}

Figures $3 a$ \& $b$ about here

Figure 2 a represents the base case - multiple imputation with complete data. The data suggest that the intervention is associated with a greater number of paid hours (though the standard error is greater than the mean - the difference is not statistically significant); it is also more costly. Costs of the work-focussed intervention were estimated at $£ 136$ per person on average. Only if the decision-maker is willing to pay about $f 100$ per paid hour does the intervention reach a $50 \%$ chance of being cost-effective. If we remove the individual who had 70 hospital days from the analysis, Figure $2 \mathrm{~b}$ shows that the difference in cost between the groups diminishes, without affecting the difference in effectiveness, so that the apparent cost-effectiveness rises. (Recall that this individual had been assigned to the intervention group.) The decision-maker needs to be willing to pay about $£ 30$, rather than $£ 100$, per paid hour for the intervention to reach a $50 \%$ chance of being cost-effective. Still, even if the decision-maker were willing to pay $f 100$ per paid hour, the probability of the intervention being cost-effective would only reach about $66 \%$. 
Finally, Figures $3 a$ and $3 b$ suggest that, if one abstracts from two unusual individuals with, in one case, no hours of intervention but a high number of paid hours per week, and in the other case, 9 hours of psychological intervention but no paid hours, there does seem to be a possible dose-response relationship between hours of work-focused psychological intervention and paid hours.

\section{Discussion and implications}

We found no statistically significant differences between IPS alone and IPS with workfocussed counselling at any time point on the primary or secondary outcome measures. While the study does provide some modest encouragement for exploring further the potential for enhancing IPS with some form of work-focussed counselling, the adjunct intervention would need to produce a practically significant increase in hours worked to be considered cost-effective. Waghorn et al. (2009, Table 2) list a range of opportunities for occupational therapists to enhance employment support for people with mental health problems, through their professional input as advocates, consultants and practitioners. The findings reported here may be read in the light of other evidence about 'work-related selfefficacy', which the same authors define as 'confidence to perform core activities at a specific task level', and put forward as an area where occupational therapy expertise is relevant.

The results also raise a number of learning points which should inform the implementation of such interventions and the design of future trials of this or similar occupational therapy interventions. First, the planned sample size was overoptimistic. Despite full co-operation from senior managers in the service studied and a context amenable to research, organisational issues - reorganisation, overcrowded offices, and the availability of care coordinators to provide the practical help required to implement the trial, proved disadvantageous. Second, provision of employment specialists proved more irregular than intended. Altogether there were 30 months of employment support worker time invested in the study over a time period of 2 years to treat 74 people. In fact, some people $(N=10)$ received only two months of employment specialist support. Studies of IPS (e.g. Perkins, 2005; Rinaldi and Perkins, 2007; Boyce et al., 2008) highlight the importance to service 
users' confidence of the continuity of this contact. Thirdly, the work-focussed counselling intervention was very much a pilot. Six sessions were offered, but participants could stop at any point. Only six people took up all available sessions and it is unlikely that a low-intensity intervention would be very powerful. It is also possible that study's intervention was not sufficiently different from standard IPS in the benefits derived by individual service users. Both constituted a supportive relationship with a focus on real-world problems; perhaps that is sufficient to enable a person to pursue his or her work aspirations effectively.

Two further issues were raised in the implementation of the study. Difficulties were experienced in completing some of the psychosocial measures, in particular the DEX and BFNE. More straightforward and user-friendly measures would be preferable if the trial were to be repeated. Furthermore, the addition of specific anxiety and depression measures would be helpful considering the popularity of the anxiety and depression topics among participants. Although receiving CBT was an exclusion criterion for the study, it emerged that a number of participants $(N=8 ; 5$ intervention and 3 control) did in fact start seeing clinical psychologists receiving CBT-type therapy after entering the study, either weekly (3) or fortnightly (5). Given the strong CBT evidence base, future trials should postpone the start of generic CBT while employment-focussed interventions are being studied.

\section{Limitations}

The high drop-out rate is the major limitation to this study. Of the 32 who dropped out, 15 were part of the intervention arm and 17 were lost to the control arm. Although no differences were found in the clinical profile nor the psychometric scores of these two arms, younger individuals and those who were not actively using the services on offer were more likely to drop out of the study. Younger individuals present greater likelihood of relapse and therefore this could have increased the probability of their dropping out (Lysaker and France, 1999).

A hostile labour market prevailed throughout the period of the trial with escalating unemployment figures in the general population. The effects on the trial cannot be 
ascertained, but comparison can be made between the study participants and people across England and Wales who were unemployed and receiving Job Seeker Allowance during the same period: The Department of Work and Pensions (DWP) apply an outcome criterion of 13 weeks of continuous paid work, and the national results of the DWP Work Programme were reported in September 2013 (Centre for Economic and Social Inclusion, 2013). This found that $11 \%$ of the general unemployed population, who were not known to have severe mental illness, succeeded in attaining employment between July 2012 and June 2013. If we apply the same 13 -week continuous employment measure, $20 \%$ of the participants in this study succeeded retaining work for 13 weeks within 12 months despite the disadvantage of severe mental health problems.

\section{Conclusion}

The learning points about the study could inform future studies. While the hypothesis that work-focussed counselling would make a significant improvement to IPS outcomes was not supported by the trial, the data demonstrate that, even during a recession, people with severe mental health problems can be helped to attain employment through the IPS approach. Comparison with the general population suggests that the effects of the recession were not as detrimental to the participants in our study as to the unemployed population as a whole. This may arguably be because the IPS approach is more effective than other employment support approaches available to the general population.

\section{Key message}

Occupational therapy can offer promising enhancements to IPS, but evaluating their marginal benefit would require a robust design that is protected against the vicissitudes of organisational change in the care environment.

\section{What the study has added}

The study has shown that IPS can be successfully delivered despite a negative economic climate in a UK context, and that it is feasible deliver work-focussed counselling as an adjunct intervention.

\section{Competing interests}


The authors declare that they have no competing interests.

\section{Authors' contributions}

AA obtained ethical clearance, collected the data and undertook data analysis, NC designed, delivered and evaluated the psychological intervention, overseen by MM who also undertook the additional analysis. BG analysed the data and generated the statistical comparisons. EL oversaw the costs analysis, while ZC performed this. JS conceived, managed and led the study. All authors contributed to the manuscript and approved the final version.

\section{Acknowledgements}

Phil Bilzon, Erica Bore, Emma Holmes, Professor Peter Liddle, Maria Griffin, Catherine Pope, Jayne Simpson, Julie Swann, Nigel Taylor, Eric Wodke and Shirley Woolley contributed their skills and knowledge to this study. We are grateful to the community health teams that participated and of course above all to the individuals who consented to join this study. The research was funded by the NIHR CLAHRC-NDL programme (2008-2013). The views and opinions expressed here are those of the authors and do not necessarily reflect those of the CLAHRC-NDL programme, NIHR, NHS or the Department of Health. Grant number RC08B2. 


\section{References}

Arbesman M and Logsdon DW (2011) Occupational therapy interventions for employment and education for adults with serious mental illness: a systematic review. American Journal of Occupational Therapy 65 (6), 238-46.

Becker DR, Smith J, Tanzman B, et al. (2001) Fidelity of supported employment programs and employment outcomes. Psychiatric Services, 52, 834-836.

Beecham J and Knapp M (1992) Costing psychiatric interventions. In Thornicroft G, Brewin C and Wing J (eds.) Measuring Mental Health Needs. London: Gaskill, pp179-190.

Bond GR, Becker DR, Drake RE et al. (1997) A fidelity scale for the Individual Placement and Support model of supported employment. Rehabilitation Counselling Bulletin, 40, 265-284. Bond GR, Drake RE, and Becker DR (2008) An update on randomized controlled trials of evidence based supported employment. Psychiatric Rehabilitation Journal, 31, 280-289. Boyce, M, Secker, J, Johnson, R, et al. (2008) Mental health service users' experiences of returning to paid employment. Disability and Society, 23(1) 77-88.

Boycott N, Akhtar A, Schneider J (2015) "Work is good for me": views of mental health service users seeking work during the UK recession, a qualitative analysis. Journal of Mental Health, 24 (2) 93-97.

Boycott N, Schneider J, McMurran M (2012) Interventions to Enhance the Effectiveness of Individual Placement and Support: A Rapid Evidence Assessment, Rehabilitation Research and Practice Article ID 382420, 8 pages, doi:10.1155/2012/382420.

Burgess PW, Alderman N, Wilson BA et al. (1996) Validity of the battery: Relationship between performance on the BADS and ratings of executive problems. In BA Wilson (Ed.), BADS: Behavioural assessment of the dysexecutive syndrome manual. Bury St Edmunds, UK: Thames Valley Test Company pp. 18-19.

Burns T, Catty J, Becker T, et al. (2007). The effectiveness of supported employment for people with severe mental illness: a randomised controlled trial. The Lancet 370: 1146-1152. doi: 10.1016/S0140-6736(07)61516-5

Bush P, et al. (2009) The long-term impact of employment on mental health service use and costs for persons with severe mental illness. Psychiatric Services 60(8): 1024-31. 
Centre for Economic and Social Inclusion (2013) Briefing paper: Measuring Work

Programme performance. Retrieved from:

http://stats.cesi.org.uk/Measuring WP Performance.pdf

Coldham EL, Addington J, Addington D. (2002) Medication adherence of individuals with a first episode of psychosis. Acta Psychiatrica Scandinavica 106 (4): 286-290.

D'Zurilla TJ, Nezu AM and Maydeu-Olivares A (2002) Manual for the Social Problem-Solving Inventory, Revised. London: Multi-Health Systems. (www.mhs.com)

Dartmouth IPS Supported Employment Center (2012) Core Principles of IPS Supported Employment. Dartmouth IPS Supported Employment Center.

http://www.dartmouth.edu/ ips/page29/page31/page31.html.

Drake, RE, and Bond, G. (2014) Introduction to the special issue on individual placement and support. Psychiatric Rehabilitation Journal, 37(2), 76-78.

EuroQol Group (1990) EuroQol: a new facility for the measurement of health related quality of life. Health Policy 16: 199-208.

IPS Dartmouth Supported Employment Center IPS Resources for Trainers and Fidelity Reviewers http://www.dartmouthips.org accessed 2592015.

Kilian, R et al. (2011) The relationships between employment, clinical status, and psychiatric hospitalisation in patients with schizophrenia receiving either IPS or a conventional vocational rehabilitation programme. Social Psychiatry and Psychiatric Epidemiology 47(9): 1381-1389.

Kinoshita Y, Furukawa TA, Kinoshita K, Honyashiki M, Omori IM, MarshallM, Bond GR, Huxley P, Amano N, Kingdon D. (2013) Supported employment for adults with severe mental illness. Cochrane Database of Systematic Reviews, Issue 9. Art. No.:CD008297. DOI: 10.1002/14651858.CD008297.pub2.

Knapp M, Patel A, Curran C, et al. (2013) Supported employment: cost-effectiveness across six European sites. World Psychiatry 12(1): 60-68. doi:10.1002/wps.20017

Leary MR (1983). A Brief Version of the Fear of Negative Evaluation Scale. Personality and Social Psychology Bulletin 9 (3): 371-375. doi: 10.1177/0146167283093007 
Lerner D, Adler DA, Chang $\mathrm{H}$ et al. (2004a) The clinical and occupational correlates of work productivity loss among employed patients with depression. Journal of Occupational and Environmental Medicine 46: S46-S55.

Lerner, D, Adler, DA, Chang, $\mathrm{H}$ et al. (2004b) Unemployment, job retention and productivity loss among employees with depression. Psychiatric Services 55: 1372-1378.

Lysaker PH, and France CM (1999) Intervention as an element in supported employment for persons with severe and persistent mental illness. Psychiatry 62(3): 209-221.

Marshall T, Goldberg, RH, Braude L, Dougherty RH, Daniels AS, Ghose SS, Preethy G, DelfinRittmon ME (2014) 2014, Supported Employment: Assessing the evidence. Psychiatric Services 65(1): 16-23.

Marwaha S, Johnson S, Bebbington P et al. (2007) Rates and correlates of employment in people with schizophrenia in the UK, France and Germany. British Journal of Psychiatry 191: 30-37. doi: 10.1192/bjp.bp.105.020982

Perkins DV, et al. (2005) Program evaluation from an ecological perspective: supported employment services for persons with serious psychiatric disabilities. Psychiatric Rehabilitation Journal 28(3): 217-24.

Priest B and Bones K (2012) Occupational therapy and supported employment: is there any added value? Mental Health and Social Inclusion 16: 194-200.

PSSRU (2013) Unit Costs of Health and Social Care. Available at: http://www.pssru.ac.uk/project-pages/unit-costs/2012/

Rinaldi M and Perkins R (2007) Implementing evidence-based supported employment. Psychiatric Bulletin 31: 244-249.

Rose V. and Perz J (2005) Is CBT useful in vocational rehabilitation for people with a psychiatric disability? Psychiatric Rehabilitation Journal 29:56-58.

Rosenberg M (1965) Society and the adolescent self-image. New York: Basic Books. Rowley, E, Morris, R, Currie, G et al. (2012) Research into practice: Collaboration for Leadership in Applied Health and Social Care Research (CLAHRC) for Nottinghamshire, 
Derbyshire, Lincolnshire (NDL). Implementation Science 2012; 7:40. doi: 10.1186/17485908-7-40.

Schneider J, Boyce M, Johnson R et al. (2009) Impact of supported employment on service costs and income of people with mental health problems. Journal of Mental Health 18(6): 533-542.

Schneider J, and Akhtar A (2012) Implementation of Individual Placement and Support: The Nottingham Experience. Psychiatric Rehabilitation Journal 35 (4): 325-332.

Schneider J, Beeley C, and Repper J (2011). Campaign appears to influence subjective experience of stigma. Journal of Mental Health 20(1) 89-97.

Schneider J, et al. (2009) Impact of supported employment on service costs and income of people with mental health needs. Journal of Mental Health 18(6): 533-542.

Swanson, S \& Becker, D (2011) Supported employment: A practical guide for practitioners and supervisor. 2nd edition. Hazelden Publishing \& Educational Services, Center City, Minnesota.

Waghorn, G, Lloyd, C, Clune, A. (2009) Reviewing the theory and practice of occupational therapy in mental health rehabilitation, British Journal of Occupational Therapy 72(7) 314323.

Ware JE, Kosinski M, Turner-Bowker DM et al. (2002) How to Score Version 2 of the SF-12 Health Survey (With a Supplement Documenting Version 1). Lincoln, RI: Qualitymetric Incorporated. 